\title{
X-56A Structural Dynamics Ground Testing Overview and Lessons Learned
}

\author{
Alexander W. Chin ${ }^{1}$, Samson S. Truong ${ }^{2}$, and Natalie D. Spivey ${ }^{3}$ \\ NASA Armstrong Flight Research Center, Edwards, CA, 93523, USA
}

The X-56A Multi-Utility Technology Testbed (MUTT) is a subscale, fixed-wing aircraft designed for high-risk aeroelastic flight demonstration and research. Structural dynamics ground testing for model validation was especially important for this vehicle because the structural model was directly used in the development of a flight control system with active flutter suppression capabilities. Structural dynamics ground tests of the X-56A MUTT with coupled rigid-body and structural modes provided a unique set of challenges. An overview of the ground vibration test (GVT) and moment of inertia (MOI) test setup and execution is presented. The series of GVTs included the wing by itself attached to a strongback and complete vehicle at two mass conditions: empty and full fuel. Two boundary conditions for the complete-vehicle test were studied: on landing gear and suspended free-free. Pitch MOI tests were performed using a compound pendulum method and repeated with two different pendulum lengths for independent verification. The original soft-support test configuration for the GVT used multiple bungees, resulting in unforeseen coupling interactions between the soft-support bungees and the vehicle structural modes. To resolve this problem, the soft-support test setup underwent multiple iterations. The various GVT configurations and boundary-condition modifications are highlighted and explained. Lessons learned are captured for future consideration when performing structural dynamics testing with similar vehicles.

\section{Nomenclature}

$\begin{array}{ll}\text { AFRC } & =\text { Armstrong Flight Research Center } \\ \text { AFRL } & =\text { Air Force Research Laboratory } \\ \text { AW1B } & =\text { anti-symmetric first bending } \\ \text { AW1T } & =\text { anti-symmetric first torsion } \\ \text { BFL } & =\text { body flap left } \\ \text { BFR } & =\text { body flap right } \\ \text { DOF } & =\text { degrees of freedom } \\ \text { FEM } & =\text { finite element model } \\ \text { FLL } & =\text { Flight Loads Laboratory } \\ \text { CG } & =\text { center of gravity } \\ \text { FOSS } & =\text { fiber-optic sensing system } \\ \text { g } & =\text { gravity } \\ \text { GVT } & =\text { ground vibration test } \\ \text { IYY } & =\text { pitch moment of inertia } \\ \text { IMU } & =\text { inertial measurement unit } \\ \text { L } & =\text { pendulum length } \\ \text { LM } & =\text { Lockheed Martin } \\ \text { lt } & =\text { left } \\ \text { MOI } & =\text { moment of inertia } \\ & \end{array}$

${ }_{1}^{1}$ Aerospace Engineer, Aerostructures Branch / 560, AIAA senior member.

${ }^{2}$ Aerospace Engineer, Aerostructures Branch / 560, AIAA member.

${ }^{3}$ Aerospace Engineer, Aerostructures Branch / 560, AIAA member. 


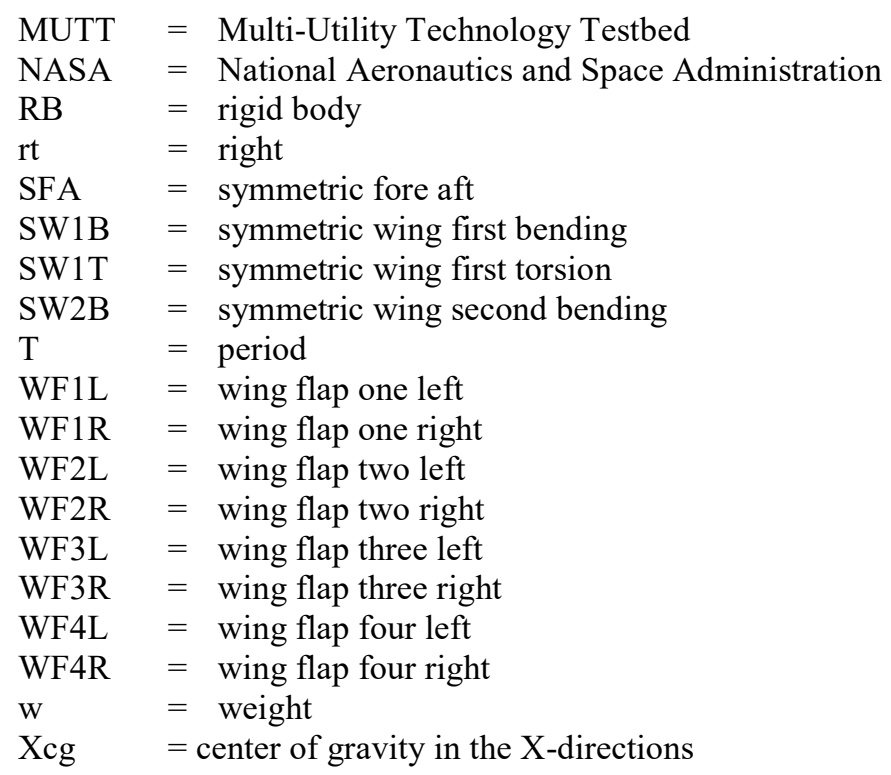

\section{Introduction}

One of the goals of the National Aeronautics and Space Administration (NASA) Aeronautics Research Mission Directorate (ARMD) is to develop high-performance technologies that increase energy efficiency and enhance the operability of aircraft. Incorporation of composite materials into aircraft in the aviation industry has allowed for major reductions in weight, thus increasing fuel efficiency. Reducing weight, however, can reduce wing stiffness, which increases the flexibility of the aircraft. Aircraft that are more flexible can become vulnerable to aeroelastic events such as flutter, divergence, and gust response. In these events, pilot reaction time may be insufficient to counteract and avoid catastrophic aeroelastic failures. Active flutter suppression (AFS) research results on the X-56A Multi-Utility Technology Testbed (MUTT) indicate that utilizing an automated aeroservoelastic controller to minimize aeroelastic encounters can ensure the safety of the vehicle and the onboard crew.

The X-56A MUTT, an unmanned aircraft developed by the Air Force Research Laboratory (AFRL) (Wright-Patterson Air Force Base, Ohio) for high-risk aeroelastic flight demonstration and research, is shown in Fig. 1. The primary objective of the X-56A MUTT is to demonstrate the feasibility of AFS and gust load alleviation by way of an aeroservoelastic controller. The X-56A MUTT was designed by the Lockheed Martin (LM) Skunk Works (Lockheed Martin, Bethesda, Maryland) under contract from the AFRL with the intent to transfer the vehicle to the NASA Armstrong Flight Research Center (AFRC) for continued flight-testing activities.[1,2]

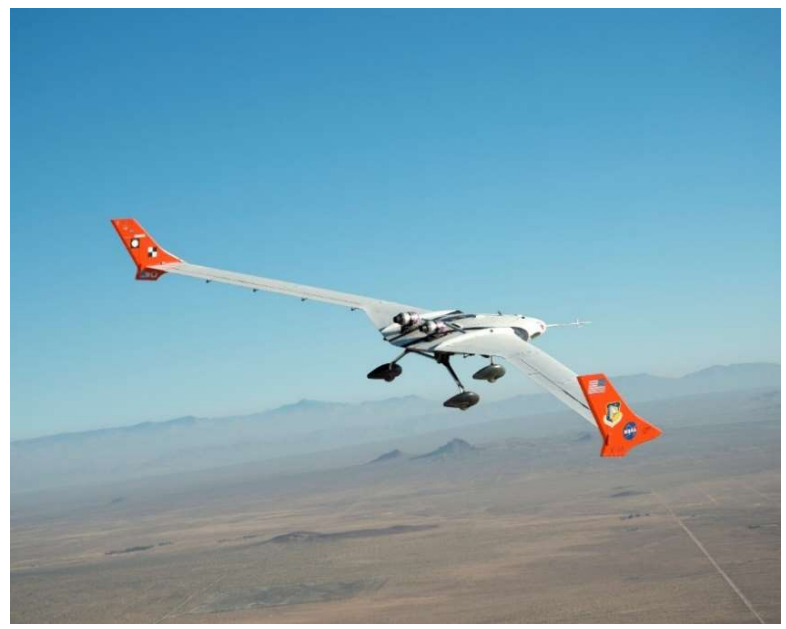

Fig. 1 The X-56A Multi-Utility Technology Testbed in flight. 
The inconsistencies of composites materials properties taken together with the X-56A manufacturing processes can result in a finite element model (FEM) that differs greatly from the actual X-56A MUTT structure. A ground vibration test (GVT) was conducted in order to mitigate these differences by validating and correlating the FEM to match the GVT results. Test-validated FEM predictions for modal analysis were subsequently used for the flutter analysis and the flight simulation controller in the loop flight simulation. In addition, mass properties testing, specifically a pitch moment of inertia (MOI) test, was performed to validate the pitch response of the vehicle. Pitch is a major component of one of the flutter mechanisms of the X-56A MUTT.

Assets of the X-56A program initially included two reusable fuselage centerbodies, named Fido and Buckeye, a rigid stiff-wing set, three flexible-wing sets, and a ground control station. The AFRC currently possesses the Buckeye fuselage centerbody, the rigid stiff-wing set, and the $\# 2$ and $\# 3$ flexible-wing sets. Flight-testing on Buckeye with the stiff wing was completed during summer 2015. Lockheed Martin was in possession of the Fido fuselage centerbody and flexible-wing set \#1 and attempted a first flexible-wing flight on November 19, 2015. This flight attempt ended in the loss of both the centerbody and the wing set upon takeoff. After the loss of the LM asset, the AFRC and the AFRL continued working toward airworthiness and flight-testing using the remaining Buckeye fuselage and wing sets. Flexible-wing set \#3 was instrumented and used for testing activities with the Buckeye fuselage. Flexible-wing set \#2 remains un-instrumented and is in storage. Structural ground tests were conducted by the AFRC on the Buckeye \#3 flexible-wing set at AFRC from spring 2016 through autumn 2016 and are the focus of this paper (which is a subset of an internal test report).[3] Flight-testing at AFRC with the flexible wings began in late summer 2017.

\section{Ground Testing}

Initial ground testing of the X-56A MUTT was performed by LM. Follow-on ground testing at AFRC was needed to address differences between the Buckeye fuselage and Fido fuselage such as additional instrumentation and equipment and potential variations in fabrication. As well, differences between wing set \#1 and wing set \#3 had to be characterized. Lockheed Martin provided a validated FEM on Fido and flexible-wing set \#1. The LM model was used as the pre-GVT reference model for changes in configuration and mass properties. The Buckeye fuselage had an increased mass, a change in mass distribution, and a shift in the center of gravity (CG) compared to the Fido fuselage. Uncertainty in composites manufacturing and how that could affect the dynamic behavior of the wings needed to be investigated. Three different structural dynamics ground tests were conducted in the Flight Loads Laboratory (FLL) at AFRC to gather test data to correlate the respective analytical counterparts. Discussion of the background, objectives, test article description, test configurations and setup, test narrative, results, and challenges are presented herein for all three tests.

\section{A. Wing-only Strongback Ground Vibration Test}

\section{Background}

In April 2016, a wing-only GVT was conducted using a strongback for both the left and right wings of flexible-wing set \#3 in the FLL High Bay. The main purpose of the GVT was to compare the wing structural frequency response to the analytical FEM and determine any differences from the left to right wings. Flexible-wing set \#3 was built from different batches of fiberglass composite material than that used to build the first two flexible-wing sets; exactly where this different batch of material was applied on the wing was not known. As a result, this test aimed to characterize any differences and provide some understanding in the modal characteristics regarding the flexible wings.

\section{Objectives}

The test objectives for the X-56A wing-only strongback GVT were to compare and validate the frequency response of both the left and right wings of flexible-wing set \#3 to the respective FEM; and to determine any manufacturing differences between the left and right wings based on post-test results.

\section{Test Article Description and Test Configurations}

Flexible-wing set \#3 was made of four plies of prepreg fiberglass material with ROHACELL ${ }^{\circledR}$ (Evonik Resource Efficiency GmbH, Germany) core for panel stability. The wing substructure was paste-bonded with a two-component epoxy. The manufacturing process used distributed weights to achieve the desired bond thickness and adhesive. Flexible-wing set \#3 differs from flexible-wing sets $\# 1$ and \#2 because the manufacturer ran out of the fiberglass material partway through the wing-skin manufacturing process. As a result, flexible-wing set \#3 was made using two different batches of the same fiberglass material. 
Two different GVTs were conducted in the FLL High Bay for flexible wing \#3: one for the left wing and one for the right wing. The left-wing test was the more extensive of the two tests. The left wing was tested first, data were collected with the GVT accelerometers, high-speed photogrammetry camera system, the fiber-optic sensing system (FOSS) [4, 5, 6, 7], and the onboard wing flight accelerometers. More time was spent testing the left wing in order to determine the ideal shaker location for exciting wing modes and providing quality test data. Time and budget constraints restricted right-wing test data collection to what could be captured using the GVT accelerometers.

\section{Test Setup}

Prior to both wings being tested, a GVT of only the 7,000-lb FLL strongback was performed to verify its modal behavior to ensure that the first structural frequency of the strongback did not couple with the primary frequency modes of the wing. Fig. 2 shows the FLL strongback, which attaches to FLL floor tracks at eight locations.

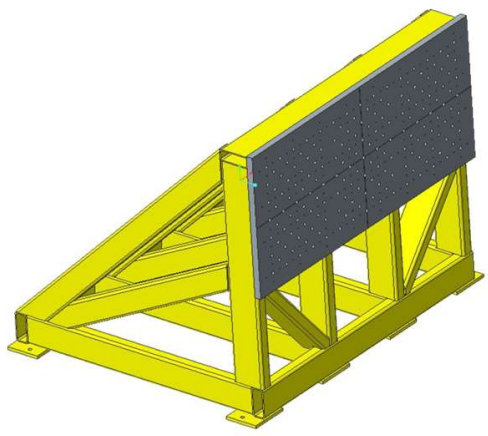

Fig. 2 The strongback used in the Flight Loads Laboratory.

Both the left and right wings of flexible-wing set \#3 were tested separately on the FLL strongback. The wings were mounted onto the strongback using the same wing attachment points that interface with the aircraft fuselage. The hole patterns between the wing attachment points and the strongback did not match, so a one-half-inch-thick steel interface adaptor plate was fabricated to connect the two.

Externally-mounted GVT accelerometers on the X-56A MUTT collected data on frequency, mode shape, and damping. Single-axis (PCB 333B32 and PCB T333B) and tri-axis (PCB T356A16) (PCB Piezotronics, Depew, New York, USA) accelerometers were located along the leading- and trailing-edge spars of the wing. A greater number of tri-axis accelerometers were placed at the wingtip because higher deflections and accelerations were expected to occur there. Instrumentation stands were placed around the mounted wing in order to offload and reduce the accelerometer wiring weight from the wing, as shown in Fig. 3 and Fig. 4.

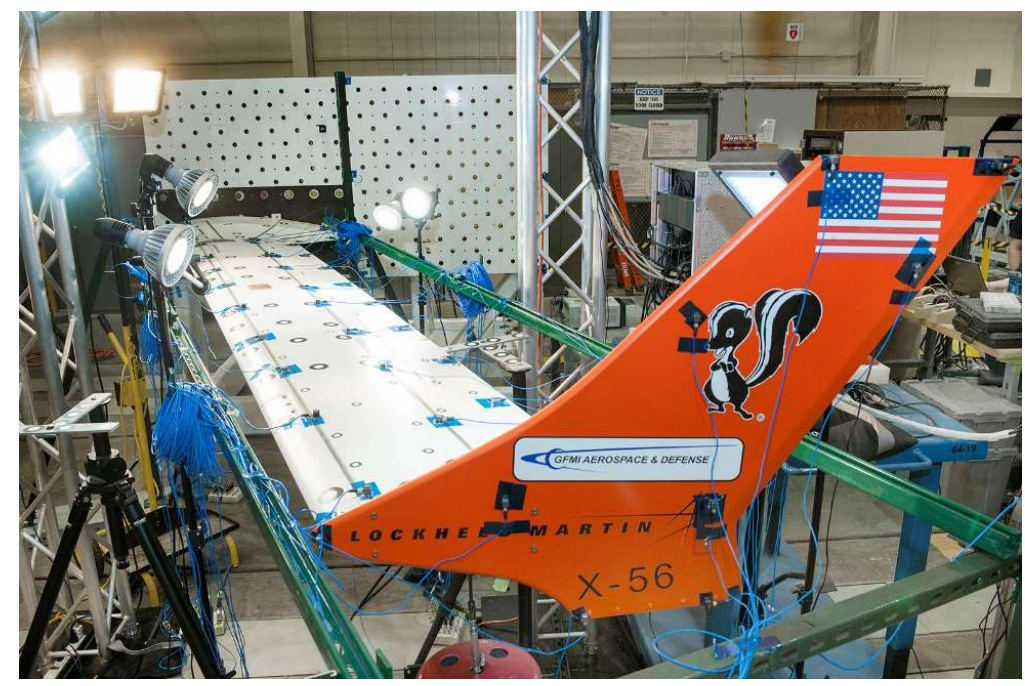

Fig. 3 The left wing strongback ground vibration test. 


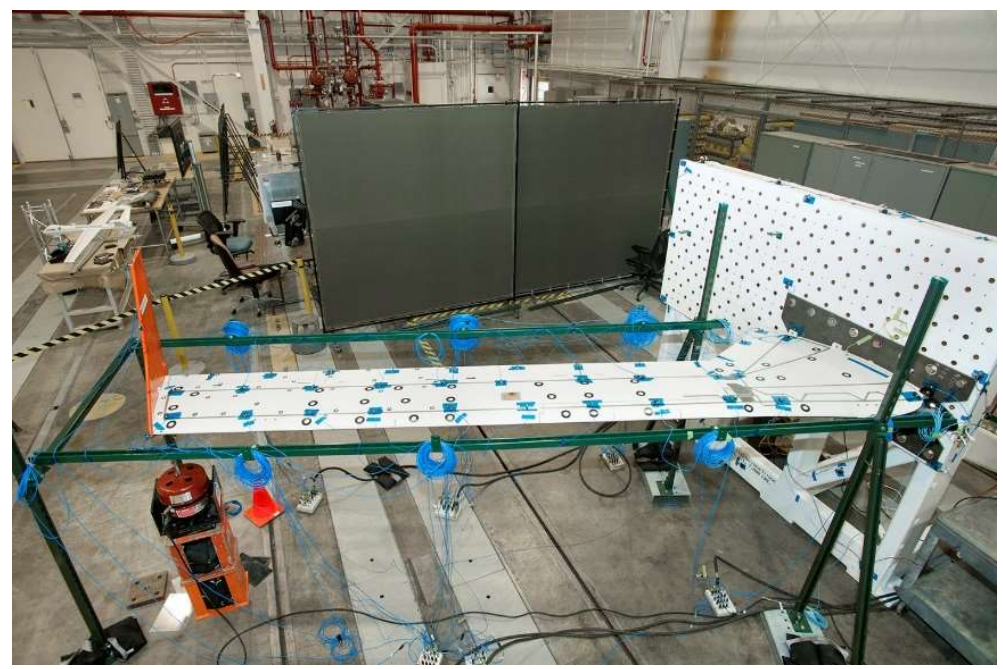

Fig. 4 The right wing strongback ground vibration test.

The accelerometer locations for the test are shown in Fig. 5 for the left wing and winglet. Note that for the rightwing test, single-axis accelerometers on the winglet were replaced with tri-axis ones to sufficiently capture the necessary degrees of freedom (DOF) to produce the quality of mode shapes desired. There were also numerous GVT accelerometers mounted on the FLL strongback to measure the response of the strongback in case it coupled with any of the wing modes.

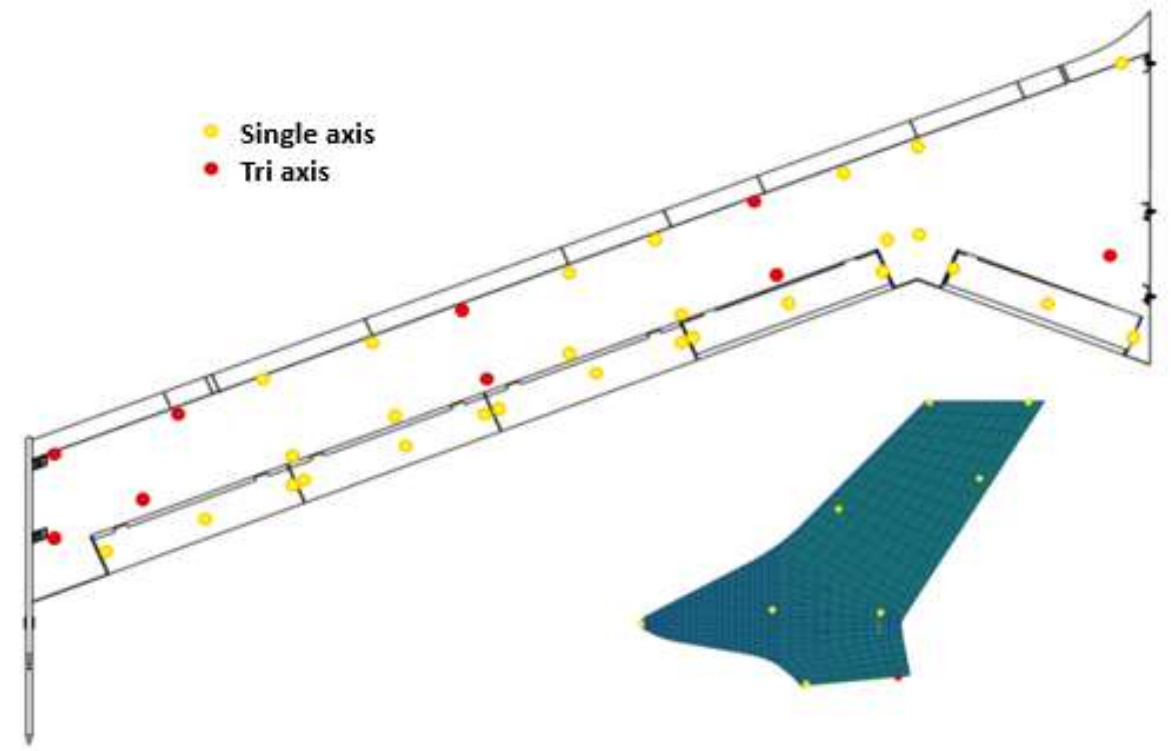

Fig. 5 Accelerometer locations for the left wing (upper left) and winglet (lower right) strongback ground vibration test.

Photogrammetry, FOSS, and flight-accelerometer data collection were performed during the left-wing test for additional verification of the modal test data and to enable future sensor research. The FOSS study was a secondary objective, intended to improve capabilities for dynamic measurements. The installation of the photogrammetry system was intended to provide a reference comparison for the FOSS system. A 1.3-megapixel high-speed camera (250 frames per second) photogrammetry three-dimensional digital image correlation (DIC) system was installed approximately $9 \mathrm{ft}$ above the left wing. The camera having a limited field of view, only the outboard portion of the wing near the wingtip could be captured. Photogrammetry DIC targets were placed a minimum of two inches apart from one another in relation to the center of the target. The rate at which the high-speed camera lens opened and closed necessitated 
additional lighting in the test vicinity (the lamps can be seen in Fig. 3). The photogrammetry target layout is shown in Fig. 6.

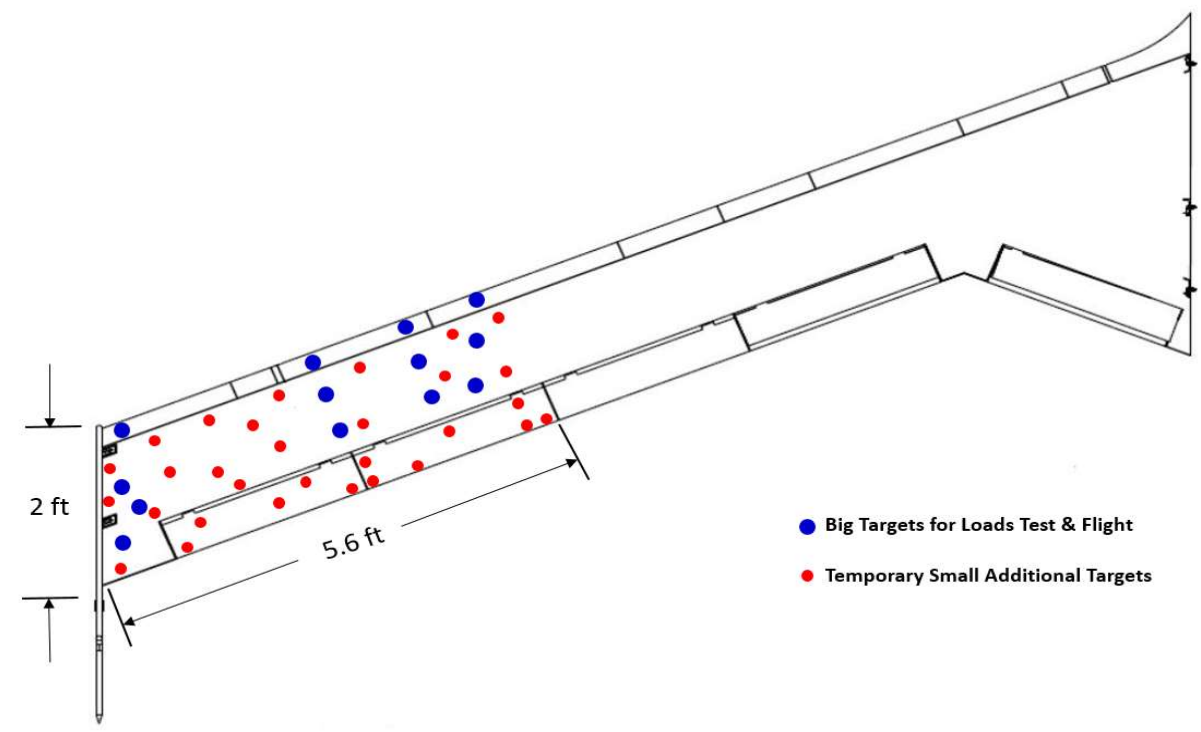

Fig. 6 The left-wing photogrammetry layout.

A 50-Hz FOSS fiber for flight-testing was installed onto the upper and lower surfaces of the left wing prior to testing. During the GVT, dynamic data were recorded using the FLL ground FOSS system with the eventual goals of determining mode shapes and emulating strain rosettes for comparison with co-located strain gages. Higher shakerforce levels were required for better quality fiber-optic shape-sensing data from larger deflections of the wing. The FOSS layout on the top and bottom of the left wing is shown in Fig. 7.
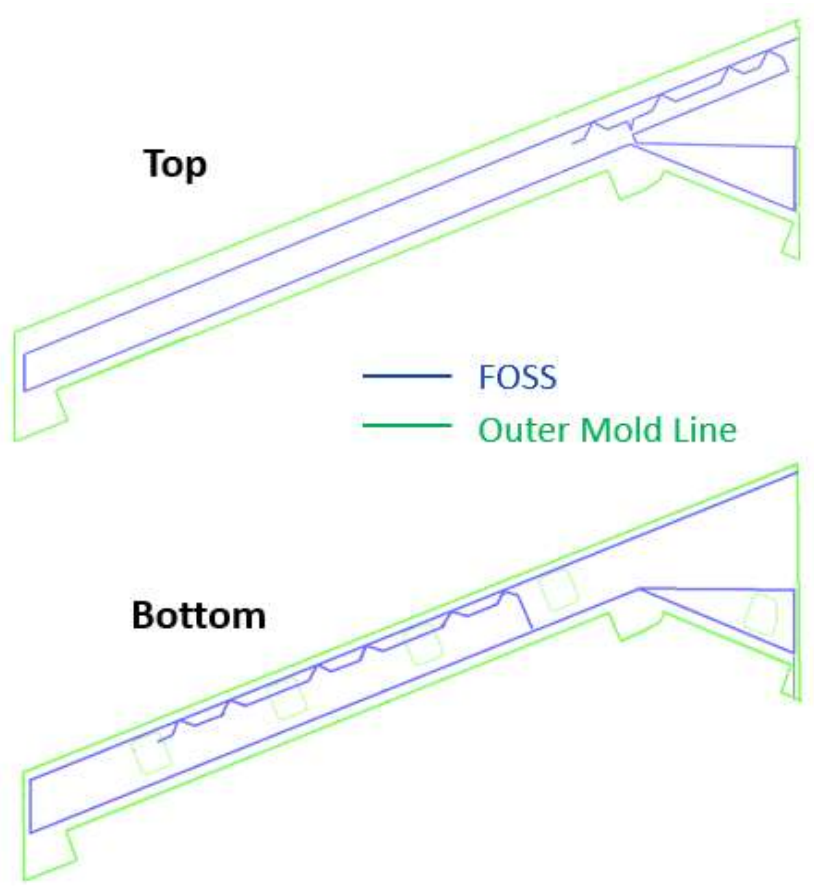

Fig. 7 The FOSS layout on the top (top) and the bottom (bottom) of the left wing.

Data were also collected using the onboard flight accelerometers (Endevco® 7290E-R-D-50-240) (PCB Piezotronics, Depew, New York, USA) for comparison with the GVT accelerometer data. The flight-accelerometer data were collected using a project laptop patched into the flight instrumentation system. Six 
primary Z-direction flight accelerometers were installed throughout the X-56A MUTT and are highlighted in red in Fig. 8. The accelerometers highlighted in yellow in Fig. 8 indicate secondary flight accelerometers in the single-axis direction. The left-wing-only test acquired data from the primary flight accelerometers on the wing.

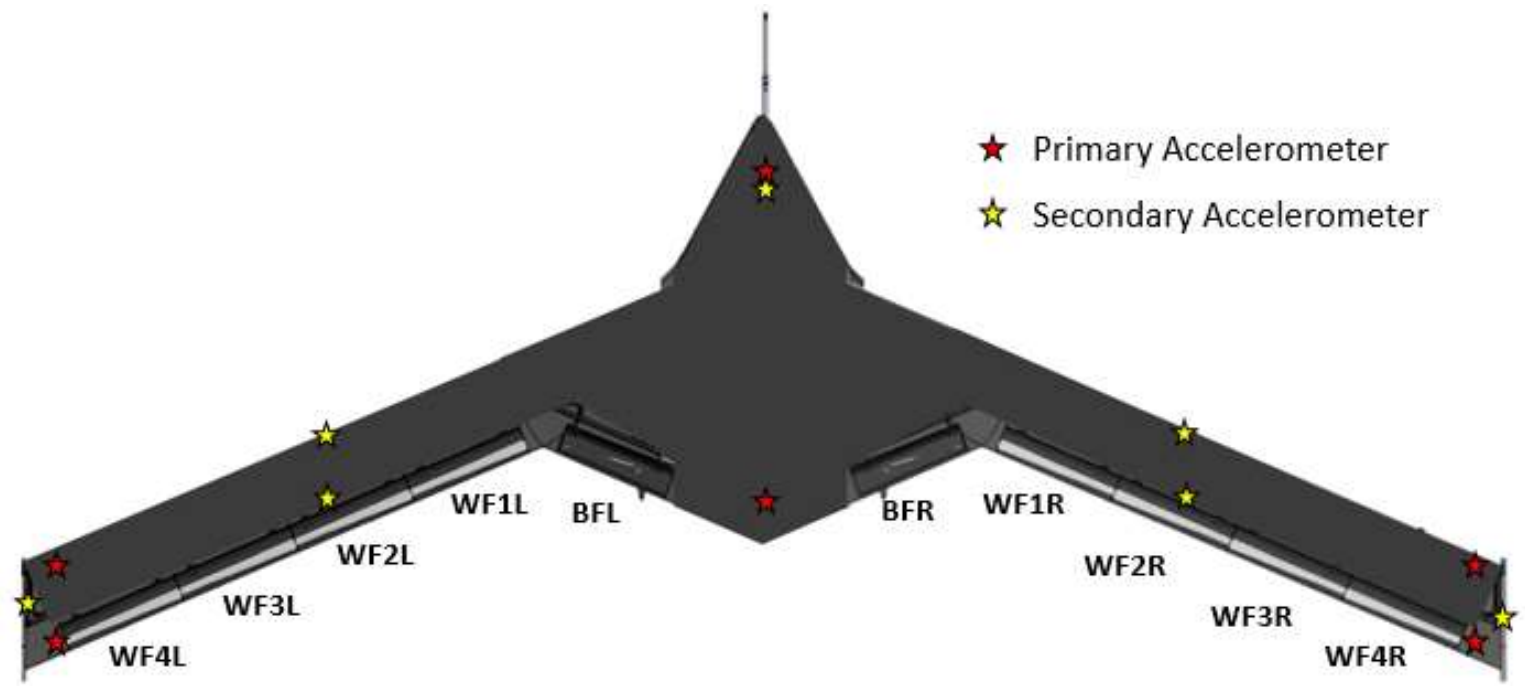

Fig. 8 The locations of the onboard accelerometers.

\section{Test Narrative}

Wing-only strongback GVT testing began on the left wing. Identifying the best shaker location and direction was one of the first priorities to enable clean mode-shape identification. A 110-lb MB Dynamics (Cleveland, Ohio, USA) electromagnetic shaker was used to excite the wing vertically at the wingtips near the winglet connection at the leading-edge spar, mid-chord, and trailing-edge spar; the leading-edge spar point also had a fore-aft excitation. In addition, lateral excitation was provided by the shaker at the top aft portion of the winglet. Additionally, impact hammer (Dytran model 5800B4) (Dytran Instruments, Inc., Chatsworth, California, USA) excitations were performed at each shaker location tested for comparison with the shaker. Vertical excitation at the leading-edge spar of the wingtip provided the best data quality. The leading-edge spar shaker setup on the right wingtip is shown in Fig. 9.

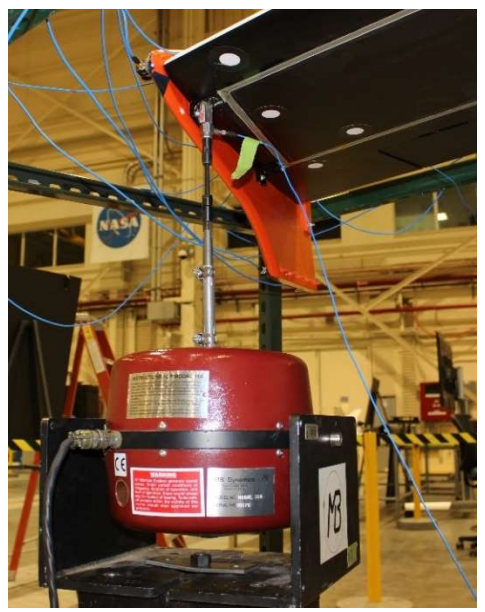

Fig. 9 The location of the leading-edge spar shaker on the right wingtip.

Another consideration was the effect of leaving the control surface actuators powered off or on. During testing, leaving the control surfaces powered off allowed them to droop with each subsequent shake run, with higher force levels causing bigger deflections. Powering-on the control surfaces locked them in place at 0 deg deflection, but slight vibrations could be felt on the wing and a humming noise could be heard close to the test article. Post-test processing 
of the data showed that leaving the control surfaces powered on and locked in place provided cleaner data; thus the control surfaces were powered on using ground power during the X-56A full-aircraft GVT.

It was determined that the ideal shaker-force level for the GVT accelerometers was approximately $0.70 \mathrm{lb}$ root mean squared (RMS). There were eight test configurations for the left-wing testing, using varying shaker force levels installed vertically at the wingtip leading-edge point. The control surfaces were powered on and off for these runs for comparison. The FOSS system required higher shaker-force levels because measurements were based on strain. A total of 88 test runs were conducted between both wings.

\section{Results}

Table 1 shows the mode shape and frequency comparison between the left and right wings. Note that accelerometers were added for the right-wing test, resulting in clearer mode shapes. In general, the left and right wings showed similar dynamic behavior.

Table 1. Ground vibration test mode shape and frequency comparison of the left and the right wing.

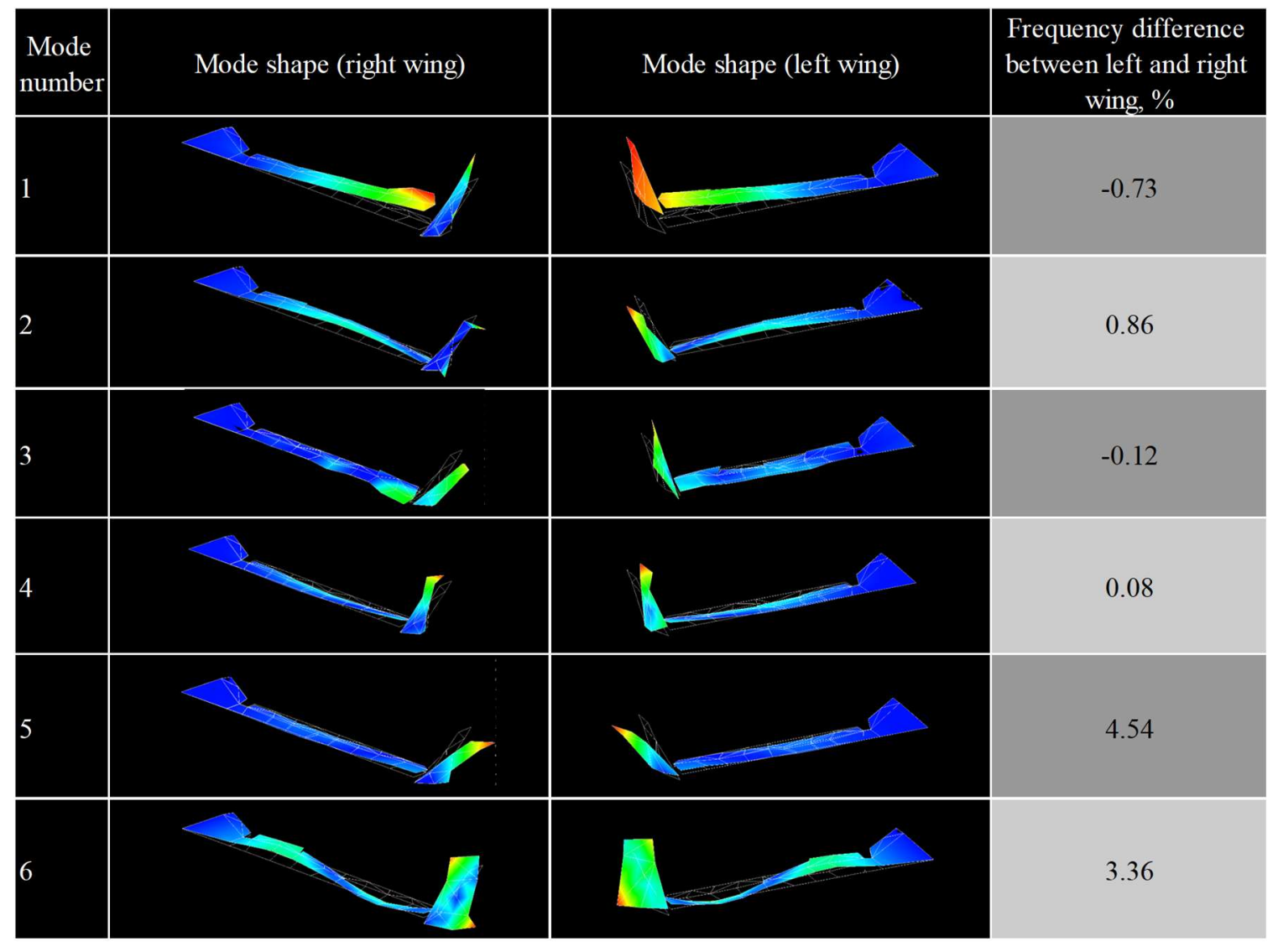

\section{Challenges}

There was uncertainty as to whether the stiffness of the strongback was sufficient for serving as a fixed boundary condition for the wing-only tests. A separate shaker test was performed only on the strongback in order to verify the frequencies of the natural modes of the strongback. The strongback was verified to have a first frequency beyond the frequency range of interest for the wings.

\section{B. X-56A Aircraft Ground Vibration Test}

\section{Background}

The X-56A full-aircraft GVT was conducted in the FLL High Bay in 2016 from August to September to investigate uncertainties in the composite fabrication, verify the stiffness connections between the wings and the fuselage, characterize modifications made to the nose and main landing gears, and account for additional instrumentation placed 
in the Buckeye fuselage centerbody bays for updating the X-56A FEM. Multiple GVTs were conducted in different $\mathrm{X}-56 \mathrm{~A}$ configurations to examine the modal behavior in full- and empty-fuel conditions in free-free (suspended above ground to simulate free-flight conditions) and on-ground (landing or taxi condition) cases. The X-56A FEM was then updated to reflect the results from the GVTs.

\section{Objectives}

The primary test objectives for the X-56A GVT were to acquire damping, frequencies, and mode shapes for each GVT test configuration; characterize and understand the unique properties and behaviors of the fuselage centerbody and flexible-wing set \#3; and provide data for FEM model updating and tuning to reduce model uncertainties between analytical and experimental modal results.

A secondary objective was to obtain FOSS and photogrammetry data to evaluate the feasibility of using the FOSS for active flutter suppression, shape control, or both.

\section{Test Article Description and Test Configurations}

For the X-56A GVT, the testing built up to the flight configuration with both the left and right wings of flexible-wing set \#3 installed on the Buckeye centerbody. The first test configuration involved only the Buckeye fuselage centerbody; the second configuration utilized the complete vehicle. Eighty pounds of aircraft fuel were used for the full-fuel test configurations. In all of the test configurations, the main landing gear was at its maximum forward position: 3.4 in ahead of the LM main landing gear configuration. Approximately $4 \mathrm{lb}$ of ballast were added to bring the CG within acceptable range. Flight-accelerometer, FOSS, and photogrammetry data were also gathered during the test once the correct shaker configurations and ideal shaker force levels were determined.

\section{Test Setup}

For the free-free GVT configurations, an overhead soft-support system was used to minimize the structural coupling by isolating the rigid-body modes from the elastic modes, simulating the free-flight condition of the X-56A MUTT during flight.

Replication of the previous LM GVT setup was not possible because a rear bungee could not be directly connected to the pick-up point between the engines because doing so would have caused permanent fuel leak problems. This restriction led to the design and construction of an interface frame, or "lifting frame." The original test setup used three bungees connected to an interface frame: one each at the left and right rear pick-up point, and one forward at the center of the X-56A MUTT. The lifting frame and its connection and pickup points are shown in Fig. 10.

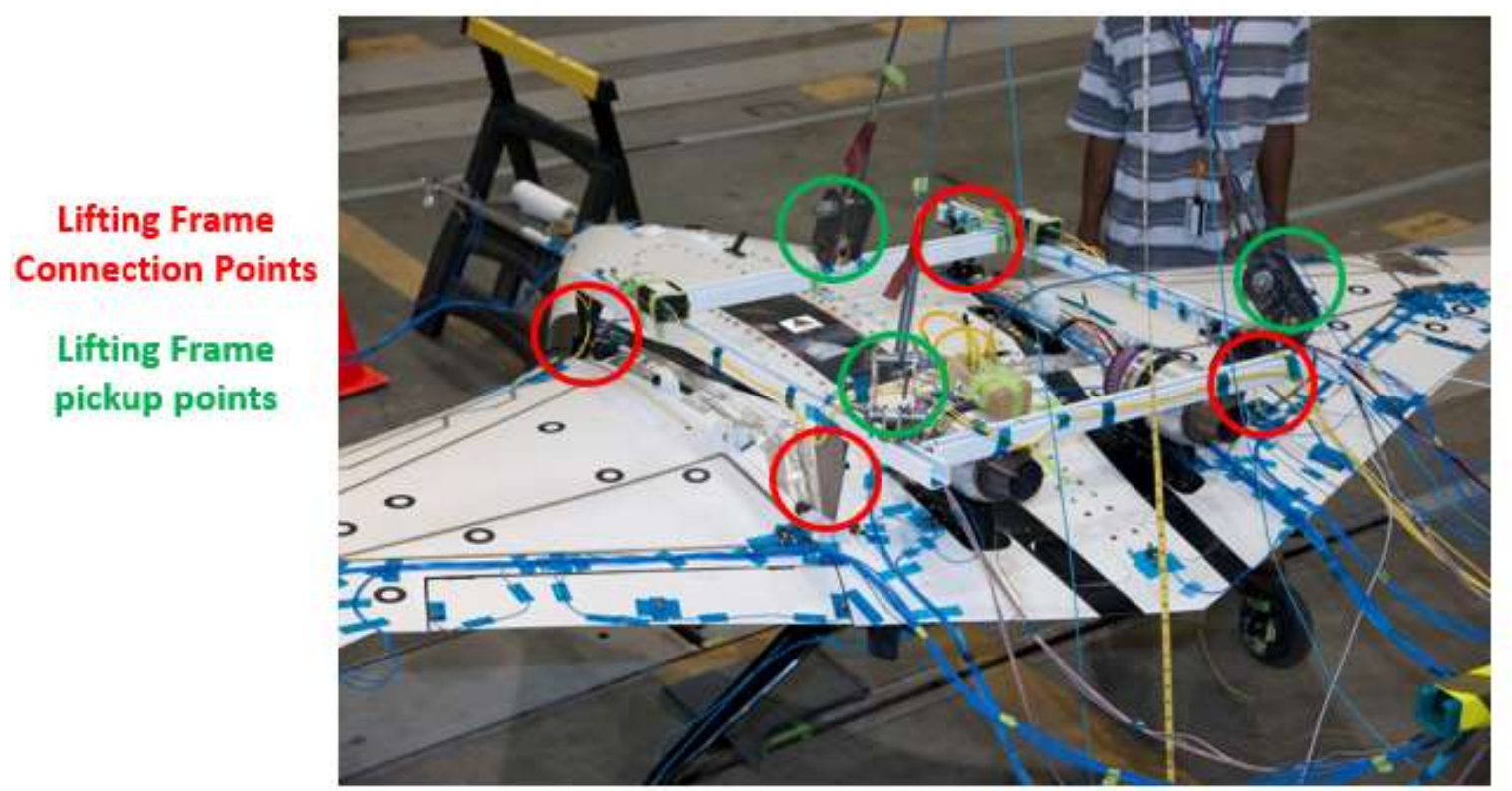

Fig. 10 The pickup points with the lifting frame connected to the X-56A Multi-Utility Technology Testbed.

The complete soft-suspension system, shown in Fig. 11, consisted of three main sections: at the top, three wirerope slings were hooked to the overhead crane and were linked with turnbuckles to the upper spreader bar. In the 
middle and underneath the spreader bar were three load cells (rated to 2,000 lb) connected to the bungees. At the bottom, the bungees connected to the vehicle lifting frame. The long bungees were designed and fabricated by Bungee America (Los Angeles, California, USA).

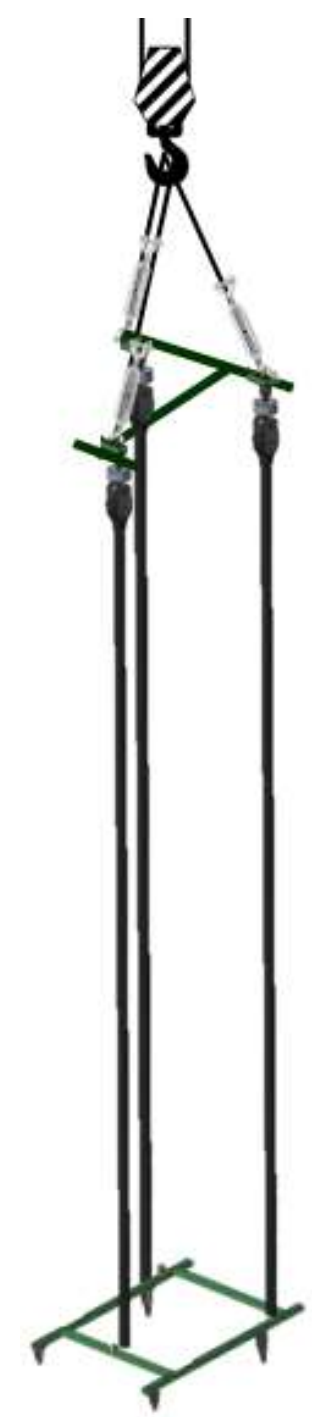

Fig. 11 The full ground vibration test soft-support system with three bungees.

The use of the long bungees was driven by cost and schedule. The project team elected not to buy new custom bungees, which would require that time and other resources be spent on characterization testing. The in-house bungees had been characterized previously, so did not require testing. Previous testing indicated that the in-house bungees had a sufficiently low frequency.

The lifting frame and the GVT hardware needed to interface the bungees to the clevises onto the lifting frame were designed and fabricated in-house. The dynamic response of the bungees was characterized to ensure that the isolation frequency of the system was low enough to be decoupled from the X-56A natural frequencies. Figure 12 shows the soft-support system bungees connected to the upper spreader bar; Fig. 13 shows the soft-support system bungees connected to the lifting frame. 


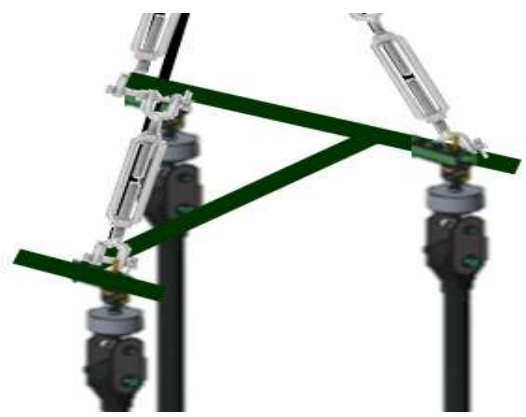

Fig. 12 The ground vibration test soft-support system connected to the upper spreader bar by three bungees.

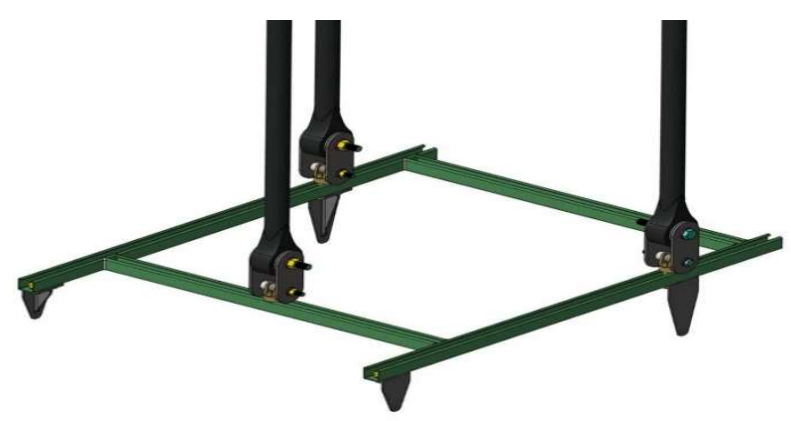

Fig. 13 The ground vibration test soft-support system connected to the lifting frame by three bungees.

The primary instrumentation for this test was GVT accelerometers. The locations of the accelerometers were based on both pre-test FEM analysis and comparison to sensor locations from the 2012 LM GVT that was performed with the FIDO centerbody and flexible-wing set \#1. The new landing gear configuration necessitated that more GVT accelerometers be installed on the gear to better characterize its dynamics. As well, the forward bungee, the right aft bungee, and the lifting frame were instrumented with accelerometers to verify whether any coupling existed between them and the X-56A MUTT. Instrumentation stands were placed behind the X-56A MUTT to offload the weight of the accelerometer wires. The accelerometer locations for the GVT are shown in Fig. 14. A total of 139 accelerometers, using a total of 259 channels, instrumented the X-56A MUTT and the soft-support system.

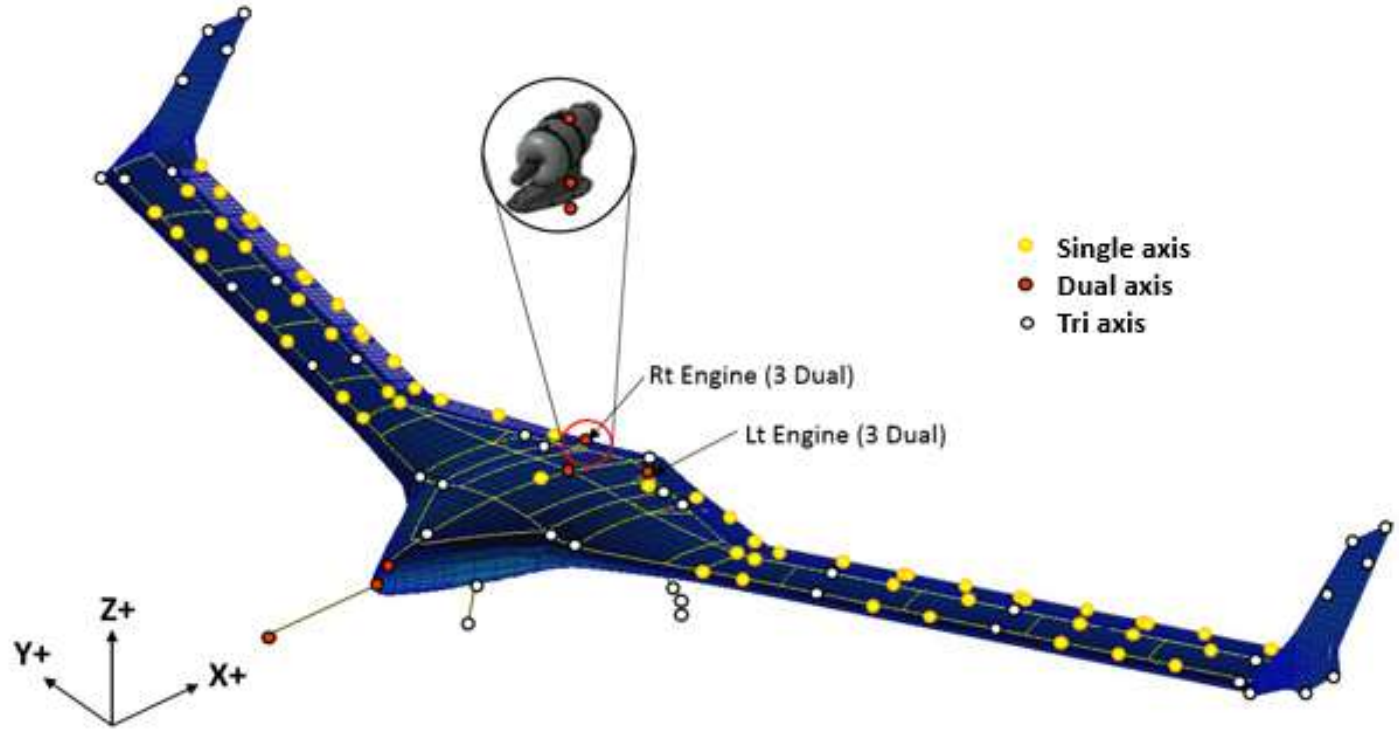

Fig. 14 The locations of the accelerometers for the ground vibration test. 
The soft-support system consisting of the lifting frame and bungees was also instrumented with accelerometers to assist with troubleshooting and to verify that the soft-support system did not interfere with the X-56A structural modes. Tri-axis accelerometers were placed at the top, bottom, and mid-length of the bungees.

\section{Test Narrative}

Prior to testing each GVT configuration, a weight and balance was performed to measure the approximate weight of the X-56A MUTT with the GVT instrumentation and XCG location. As well, for the free-free configurations, a 30-min period was allowed to enable the bungees to stretch and stabilize before the test was conducted. The first test configuration used the Buckeye fuselage centerbody only in a free-free full-fuel setup. Shaker excitations were provided vertically and laterally near the fuselage nose area. In addition, impact-hammer excitations were provided on the nose boom, main landing gear, nose landing gear, and engines. Impact-hammer excitations yielded better quality data than did the shaker.

The second configuration used the free-free Buckeye fuselage center body mated with flexible-wing set \#3, in a free-free full-fuel state with three bungees. A lifting and leveling checkout was completed prior to testing. This test was the first test configuration with the fully-assembled X-56A MUTT in free-free suspension. Both vertical and 45-deg fore-aft shakes were completed at the wingtip leading-edge spars of both the left and right wings. As the test progressed, mode-shape coupling was observed between the X-56A first symmetric bending mode and the three-bungee soft-suspension system. Initially, it was suspected that the upper bungee hardware, perhaps the spreader bar, was the source of the error. As such, two diagonal unistrut bars were installed on the spreader bar to stiffen it, but this approach did not alleviate the coupling problem. Figure 15 shows the original test setup with the three-bungee soft-support system using the lifting frame, which was connected to the center body and the spreader bar on the upper bungees.

In an attempt to eliminate the coupling of the wing first bending and the suspension system, the testing configuration was changed again to remove the upper bungee hardware completely. This approach eliminated the spreader bar interface and allowed the three bungees to be directly connected to the overhead crane hook using three wire-rope slings. This bungee soft-support configuration is also shown in Fig. 15.

In spite of this change, the multi-bungee configuration still appeared to couple with the X-56A MUTT. The soft-support configuration was then changed to a single-bungee configuration. Three wire-rope slings were required to connect from the lower test fixture frame interface at the former bungee attachment points to the lower portion of the bungee and the top of the bungee connected to the overhead crane hook directly with a shackle. The single-bungee test configuration is shown in Fig. 15. A close-up picture of the wire-sling interface between the lifting frame and the soft-support bungee is shown in Fig. 16. The three wire-rope slings now used on the lower part of the single bungee were the same slings used on the upper part of the three-bungee system. This configuration change to one bungee eliminated the coupling problem between the X-56A MUTT and the suspension system. 


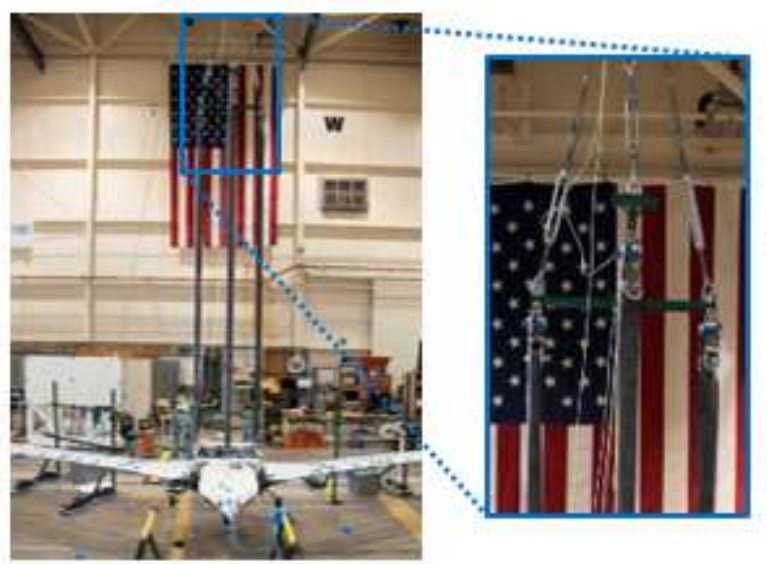

\section{Original}

Three Bungee

Suspension

System with

Spreader Bar

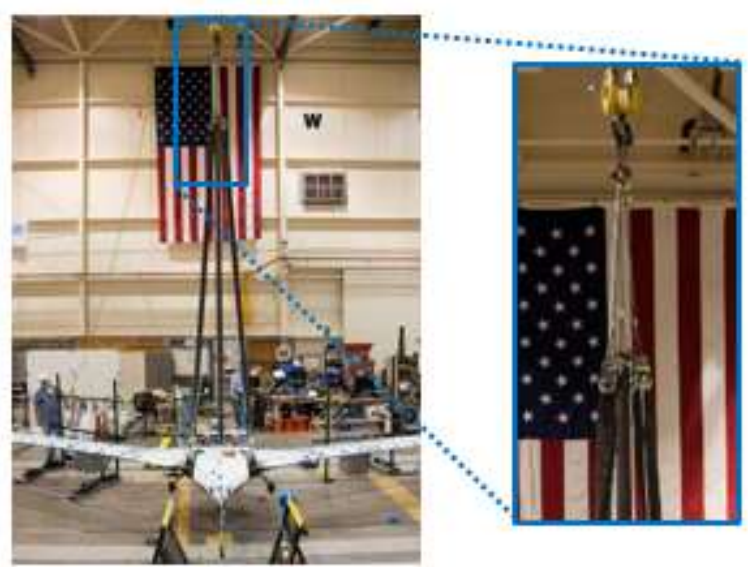

\section{Modified}

Three Bungee

Suspension

System without

Spreader Bar

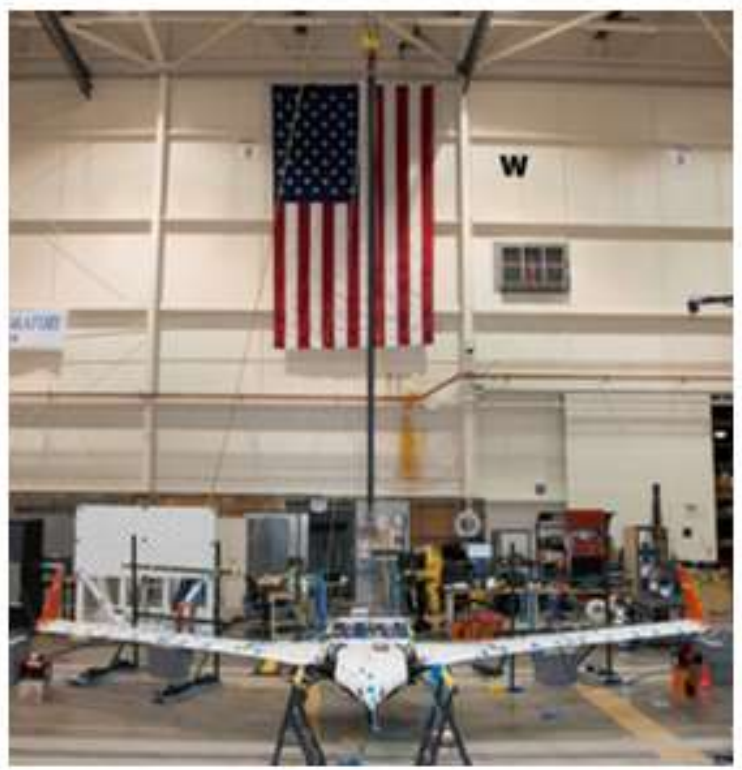

Single Bungee

Suspension

System

Fig. 15 Configuration changes to the bungee soft-support. 


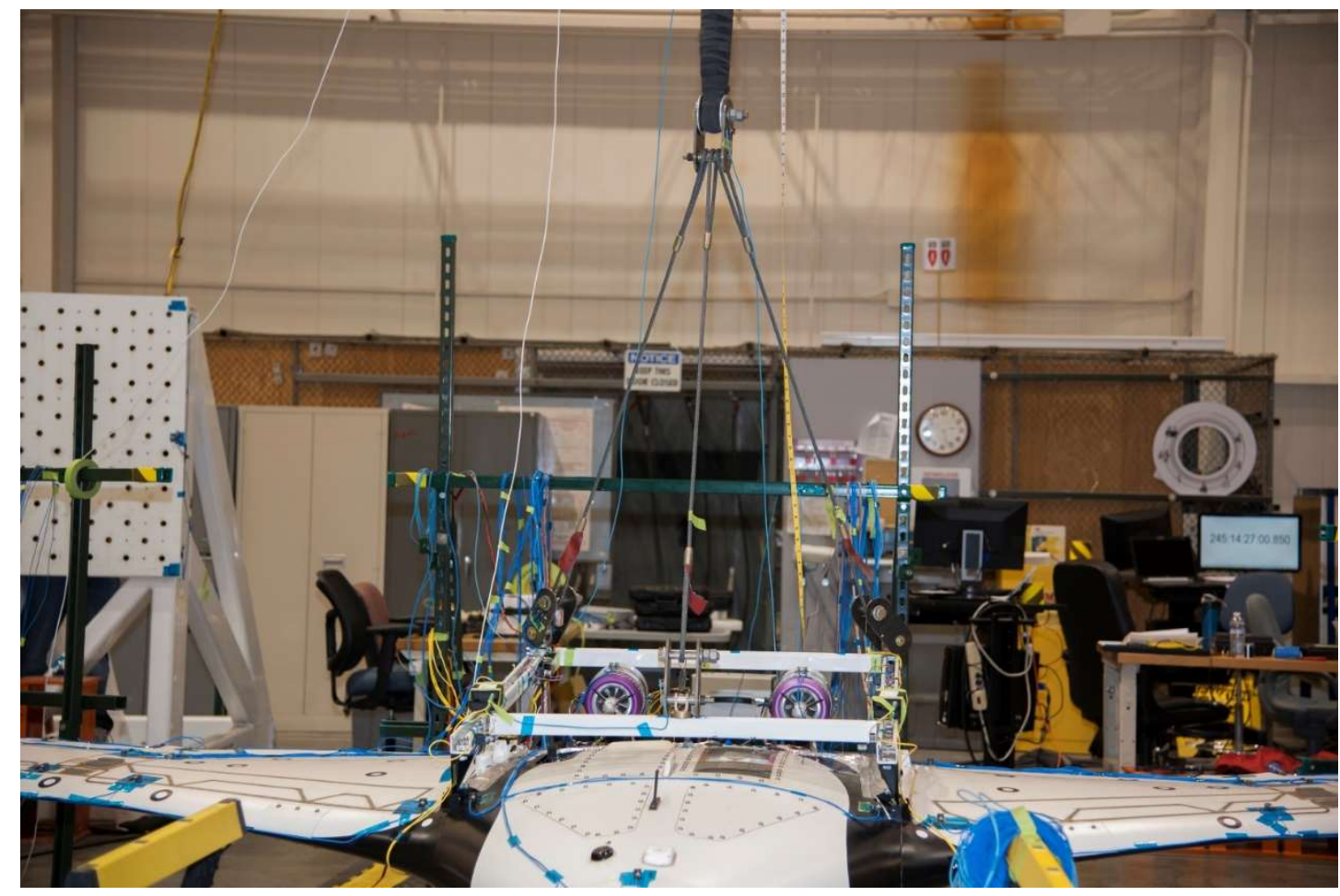

Fig. 16 The single-bungee lifting fixture interface.

Shaker- and impact-excitations were performed, as well as roll, pitch, and plunge rigid-body manual excitation tests to measure the rigid-body frequencies. The FOSS, photogrammetry, and flight-accelerometer data were collected. During the test, the results showed that there was sufficient frequency separation between the single soft-suspension system and the X-56A MUTT that coupling was no longer a problem. In the previous three-bungee configuration, the CG could be positioned between the forward and aft bungee; however, with the single-bungee configuration, alignment with the CG was more challenging to control. The remainder of the test runs in various test configurations went smoothly, including a final test configuration with the X-56A MUTT on the ground resting on its landing gear. This test configuration was used to provide dynamics response data with an on-ground boundary condition and provide a future reference for correlating the onboard flight accelerometers with the added GVT instrumentation for potential future pre-flight and post-flight frequency checks. A total of 195 test runs were conducted for the X-56A GVT.

\section{Results}

The comparison of the test-mode shapes and FEM-mode shapes for the first six modes in the empty-fuel configuration is shown in table 2 . 
Table 2. Comparison of the test-mode shapes and finite-element-model-mode shapes for the first six modes in the empty-fuel configuration.

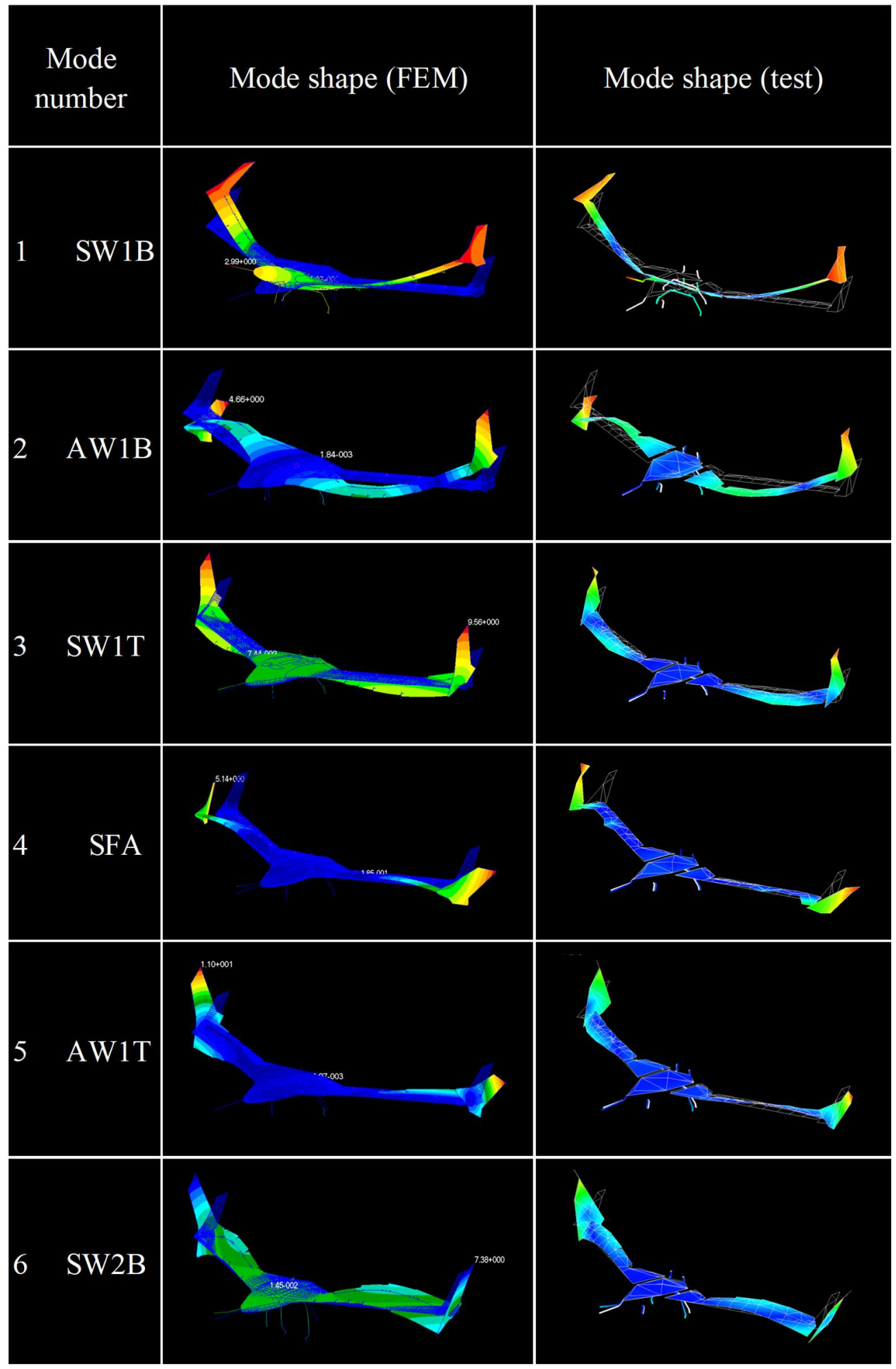


Table 3 shows the percent differences for the mode frequencies for the first six structural modes for both the empty-fuel and full-fuel test configurations.

Table 3. Percent differences between the initial Lockheed Martin finite element model and ground vibration test mode frequencies for the empty- and the full-fuel test configurations.

\begin{tabular}{|l|c|c|c|}
\hline \hline Mode number & $\begin{array}{c}\text { GVT mode } \\
\text { shape }\end{array}$ & $\begin{array}{c}\text { Difference } \\
\text { between FEM } \\
\text { and test: } \\
\text { Empty fuel, } \\
\text { percent }\end{array}$ & $\begin{array}{c}\text { Difference } \\
\text { between } \\
\text { FEM and } \\
\text { test: Full } \\
\text { fuel, percent }\end{array}$ \\
\hline \hline 1 & SW1B & -6.09 & 2.01 \\
\hline 2 & AW1B & -6.39 & -3.31 \\
\hline 3 & SW1T & -0.62 & 0.36 \\
\hline 4 & SFA & -0.04 & -1.25 \\
\hline 5 & AW1T & 1.63 & 1.27 \\
\hline 6 & SW2B & -1.31 & -0.21 \\
\hline \hline
\end{tabular}

National Aeronautics and Space Administration standards require the FEM to be within 5 percent of the test frequencies for all primary modes, or modes that significantly contribute to the flutter modes of the vehicle.[8, 9] Tuning the FEM therefore was required.

\section{Challenges}

One of the challenges of the X-56A FEM model update process was constraining symmetric wing first bending (SW1B) within frequency limits for both the empty-fuel and full-fuel cases. The GVT data showed a minimal shift in SW1B frequency between the empty- and full-fuel conditions; however, the FEM consistently showed an 8-percent frequency shift between the empty- and full-fuel conditions. This shift in frequency can be physically explained: as the fuel weight increases, the XCG moves further aft, increasing the pitching inertia and leading to a drop in the SW1B frequency.

One hypothesis focused on the effect of the boundary conditions on the rigid-body pitch of the vehicle. Post-GVT, the single-bungee setup was reviewed and scrutinized. The metal wire-sling connection to the bungee allowed the X56A MUTT to freely pivot about the sling-bungee connection (offsetting the Y-axis). The pivoting DOF was relevant, because the XCG (fore-aft) shifts between the empty- and full-fuel condition, along the direction of the pitching motion. The single-bungee and metal wire slings readjust the attitude of the X-56A MUTT to ensure the CG is directly below the bungee. A sensitivity analysis on the bungee X-location was performed to determine its effect on rigid-body and flexible modes. Figure 17 illustrates the DOF allowed by the interface between the metal slings and the single bungee. 


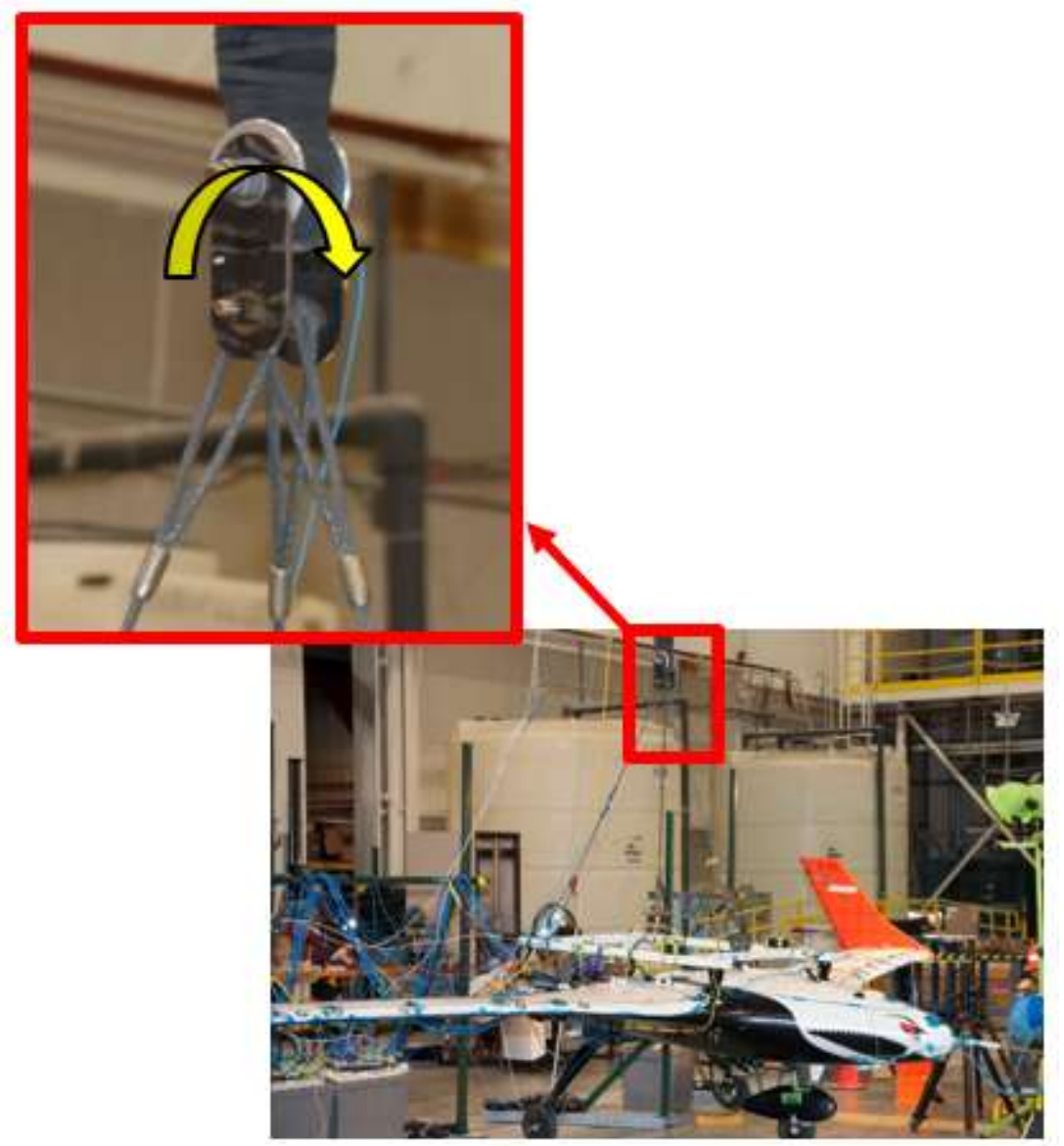

Fig. 17 The metal-slings-to-bungee pivot for the $\mathrm{X}-56$ ground vibration test.

The updated testing configuration was modeled in the FEM to better examine what effect, if any, the single-bungee boundary condition may have had on the test data. Figure 18 shows the resulting rigid-body plunge and SW1B-relative frequencies and mode shapes. Varying fuel cases and the corresponding shift in pivot location because of changes in XCG (fore-aft) location were modeled by physically changing the top pick-up constraint point in the model. A neutral pivot point represents the CG being centered under the pivot boundary condition.

Non-dimensional frequencies are presented because of the sensitivity of the actual frequency information. A clear difference in the SW1B mode frequency is seen in the FEM, which showed 1.08 SW1B frequency for empty fuel and $0.99 \mathrm{SW} 1 \mathrm{~B}$ for full fuel. When changing the boundary-condition location by moving the pivot location forward or aft, however, the SW1B frequency changes and the pitch-plunge rigid-body mode incorporates more pitching motion. The attitude of the X-56A MUTT changes as it readjusts for the CG to lie directly below the boundary-condition pivot point. A more forward CG is represented by moving the pivot forward, which shows the SW1B frequency for empty fuel moving lower: from 1.08 to $1.05 \mathrm{SW} 1 \mathrm{~B}$. A more aft CG is represented by moving the pivot aft, which shows the SW1B frequency moving higher: from 0.99 to $1.03 \mathrm{SW} 1 \mathrm{~B}$, implying that the SW1B frequencies for both the empty-fuel condition and the full-fuel condition approach each other in value as a result of the orientation of the X-56A MUTT under the pivot, which was the result observed in the test data. 


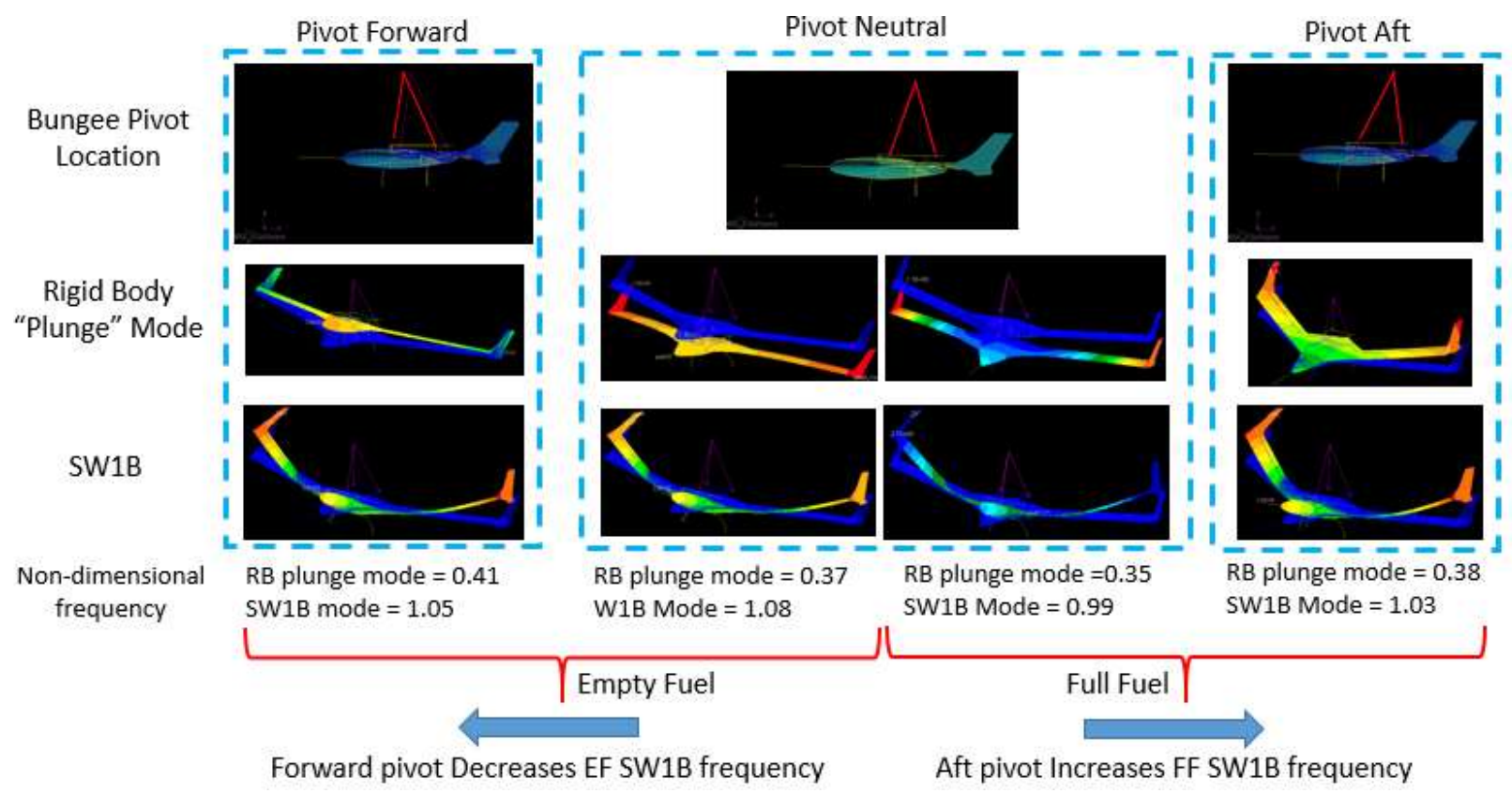

Fig. 18 Results from the bungee pivot location change study.

The location of the bungee pivot has a direct effect on the SW1B mode, but a negligible effect on the other flexible modes. Changing the location of the bungee pivot causes the rigid-body plunge mode to change as well. As the pivot moves away from the neutral pivot location, the plunge mode exhibits more of a pitching motion. The rigid-body plunge/pitch motion closely mimics the fuselage motion in SW1B but is negligible in the other primary flexible modes. Although the bungee pivot location does not completely account for non-shifting SW1B based on fuel load, the bungee pivot location was a dominant factor in obtaining accurate measurements of SW1B. All other flexible modes were not affected by bungee pivot and were consistent with what has been predicted from the FEM and observed in flight. For future tests, all potential DOF should be understood, and, if possible, isolated and constrained. Figure 19 shows how the frequency changes for the rigid-body plunge and SW1B when the pivot location changes.

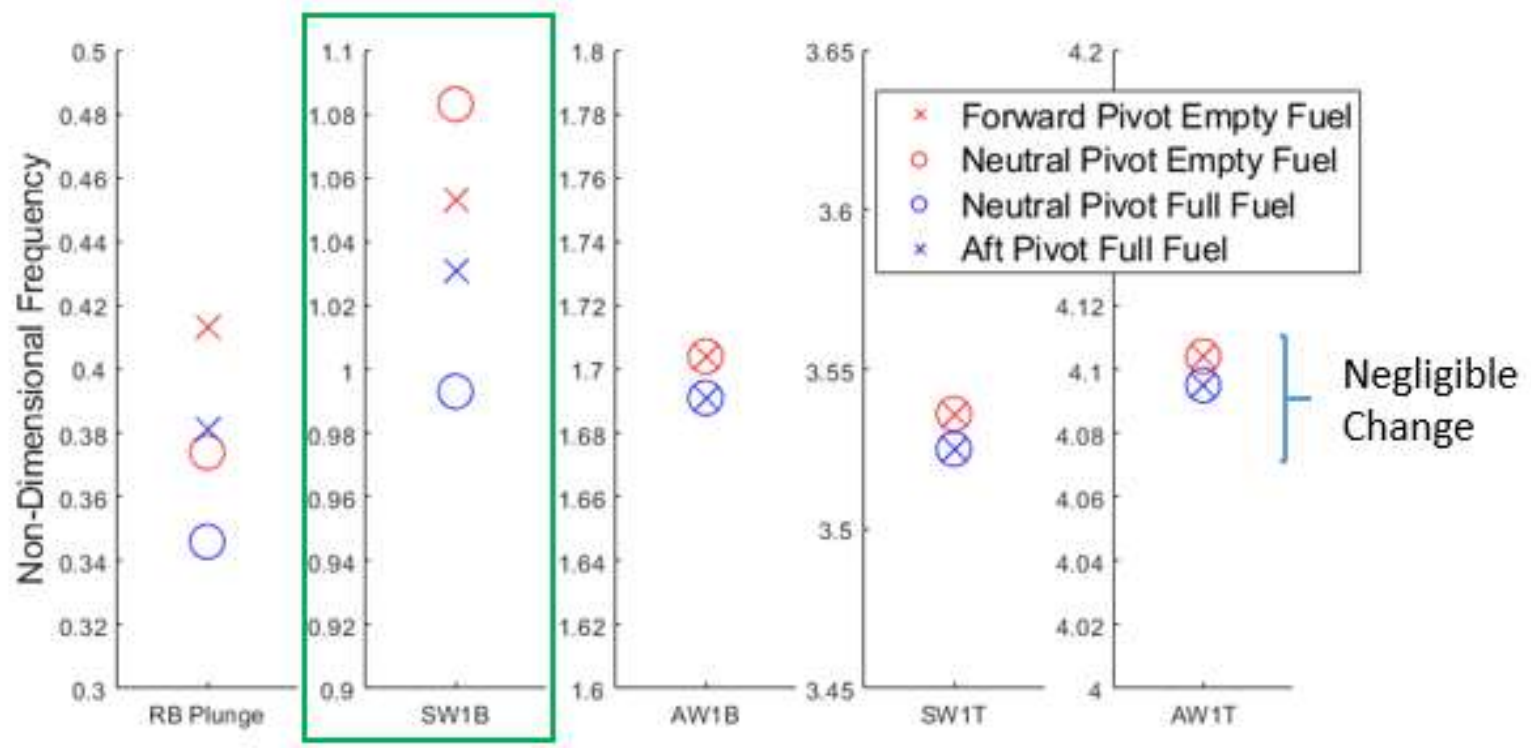

Fig. 19 Frequency shift based on bungee location change. 
Another possibility is the uncertainty error of GVT frequency response function curve-fitting techniques when comparing frequencies that are so close together. The SW1B mode occurs at low frequency, and thus is much more sensitive in error. Uncertainty from curve-fitting techniques compounds to larger errors and uncertainties for low-frequency structural modes such as SW1B.

Similar problems were encountered during the LM GVT with the Fido centerbody. The LM GVT setup yielded a pitch rigid-body frequency that was larger than expected. The higher GVT-measured pitch rigid-body frequency required modeling the bungees as part of the model correlation process.

\section{X-56A Aircraft Pitch Moment of Inertia Test}

\section{Background}

Based on the geometry and configuration of the X-56A MUTT, the pitch inertia was potentially a major component of the flutter mechanism. An IYY pitch MOI test using the compound pendulum method was performed after the GVT in the FLL to measure the inertia of the entire X-56A MUTT in the empty-fuel configuration.

\section{Objectives}

The test objectives for the X-56A IYY MOI test were to validate the analytical IYY pitch moment of inertia against test data; verify the pitch response of the flight vehicle prior to flight-testing; and improve modeling predictions for the development of flight control laws.

\section{Test Article Description and Test Configurations}

For the MOI test, all of the GVT accelerometers and wiring were removed. The X-56A MUTT was already in the fully-assembled configuration. Any loose aircraft panels were taped down and secured prior to the test, and prior to the aircraft MOI test, MOI tests of the pendulum lifting hardware were performed. Two different pendulum lengths were tested. The lifting hardware consisted of the hanger plates fabricated in-house (which act as a moment arm between the test article and the pivot point); the lifting frame was installed on top of the aircraft. The test configurations are listed Table 4 in order of occurrence.

Table 4. The X-56A pitch moment of inertia test configurations.

\begin{tabular}{|l|c|c|c|}
\hline \hline Configuration & Description & $\begin{array}{c}\text { Pendulum } \\
\text { length }\end{array}$ & $\begin{array}{c}\text { Fuel } \\
\text { condition }\end{array}$ \\
\hline \hline A & $\begin{array}{c}\text { Lifting hardware } \\
\text { only }\end{array}$ & Long & N/A \\
\hline B & $\begin{array}{c}\text { Lifting hardware } \\
\text { only }\end{array}$ & Short & N/A \\
\hline C & $\begin{array}{c}\text { X-56A + lifting } \\
\text { hardware }\end{array}$ & Short & Empty \\
\hline D & $\begin{array}{c}\text { X-56A + lifting } \\
\text { hardware }\end{array}$ & Long & Empty \\
\hline \hline
\end{tabular}

The two different pendulum lengths allowed for verification of compound pendulum test data, because even with different moment arm lengths to the pivot point of rotation, the same test article IYY should result. A pair of 20-inch hanger plates were used for the short pendulum configurations and a pair of 32-inch hanger plates were used for the long pendulum configurations.

To determine the IYY pitch moment of inertia for the X-56A MUTT, the IYY moment of inertia for the lifting hardware alone must first be determined independently. Results of the lifting hardware IYY are subtracted from the IYY of the entire assembly to calculate the pitch inertia of only the X-56A MUTT. The subtraction equation is shown in Eq. (1).

$$
I_{Y Y_{\text {aircraft }}}=I_{Y_{\text {Total }}}-I_{Y Y_{\text {Lifting Hardware }}}
$$




\section{Analysis}

Calculation of the pitch MOI required the oscillation period, T; the distance between pivot and CG, L; and the net mass of the X-56A MUTT, w.[9, 10, 11, 12, 13, 14, 15] Equation 2 shows the calculation of the MOI for the entire system.

$$
I_{y y_{\_} s y s_{-} p i v o t}=\frac{w_{1} T_{1}^{2} L_{1}}{4 \pi^{2}}
$$

Lifting hardware and fixturing MOI must be subtracted from the net MOI to determine only the MOI of the X56A MUTT. Equation 3 shows the combined calculation of the net pitch inertia of the X-56A MUTT after subtracting the inertia of the lifting hardware:

$$
I_{y y_{-} \text {vehicle }}=\frac{w_{1} T_{1}{ }^{2} L_{1}}{4 \pi^{2}}-\frac{w_{2} T_{2}{ }^{2} L_{2}}{4 \pi^{2}}-\frac{w_{3} L_{3}{ }^{2}}{g}
$$

where subscript 1 refers to the combined X-56A MUTT and lifting fixture system, subscript 2 refers to the lifting fixture system only, and subscript 3 refers to the X-56A MUTT only.

Calculation of the global CG was performed analytically based on local CG measurements and approximations of the X-56A MUTT, lifting frame, and hanger plates CG. Manual tape measure and laser-tracker measurements were used to validate the hanging lengths of the swinging test configuration with predicted analytical lengths and corresponding CG calculations. The mass contribution of the knife-edge cradle also required consideration for the total inertia of the system.

\section{Test Setup}

A metal frame was constructed for this MOI test from which the X-56A MUTT was suspended and swung. At the top of the metal frame, two knife-edge supports with a curved cradle were installed; the X-56A MUTT swung back and forth at this pivot point location. Hanger plates linked the knife-edges to the top of the lifting frame, which interfaced with the X-56A MUTT. Since the width of the metal frame is approximately $11.2 \mathrm{ft}$., the entire X-56A MUTT, which was approximately $14.5 \mathrm{ft}$ from the nose-boom tip to the aft tip of the winglet, was not able to fit into the frame from the side. Prior to testing, the X-56A MUTT had to be guided slowly, diagonally from the front, and maneuvered into the center of the inertia testing frame. Critical lift procedures had to be followed because of the electro-explosive device onboard the X-56A MUTT. The X-56A MUTT was then lifted onto a lift table, which then raised the X-56A MUTT to its connection points, where the hanger plates connected with the lifting frame. Once the connection was set, the X-56A MUTT hung in equilibrium from the metal frame as the lift table was removed from the test vicinity. Figure 20 shows a side view of the MOI hanger plates attached to the cradle and knife-edges. Figure 21 shows the lifting frame from the forward perspective in MOI testing configuration. Figure 22 shows the X-56A MUTT in the MOI testing configuration.

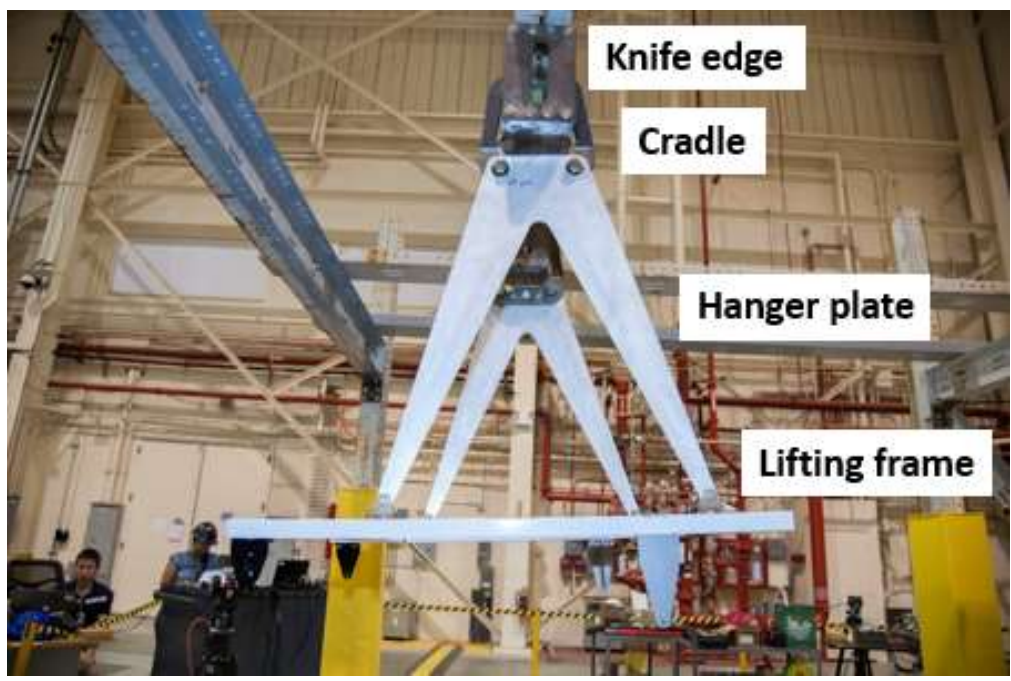

Fig. 20 Side view of the moment of inertia hanger plates. 


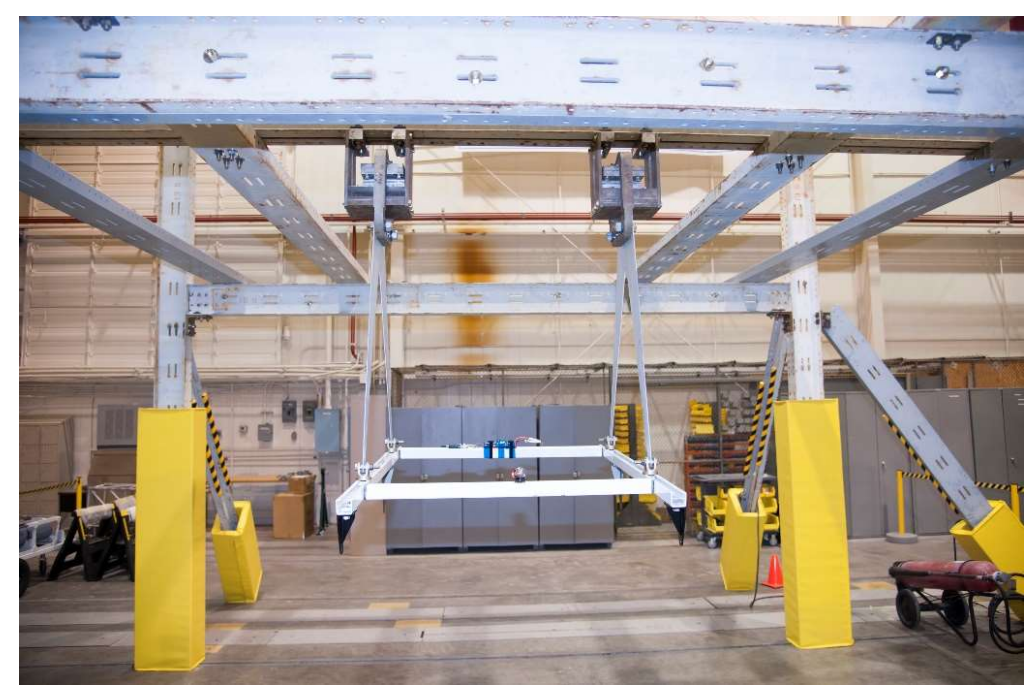

Fig. 21 Front view of the lifting frame in the moment of inertia testing configuration.

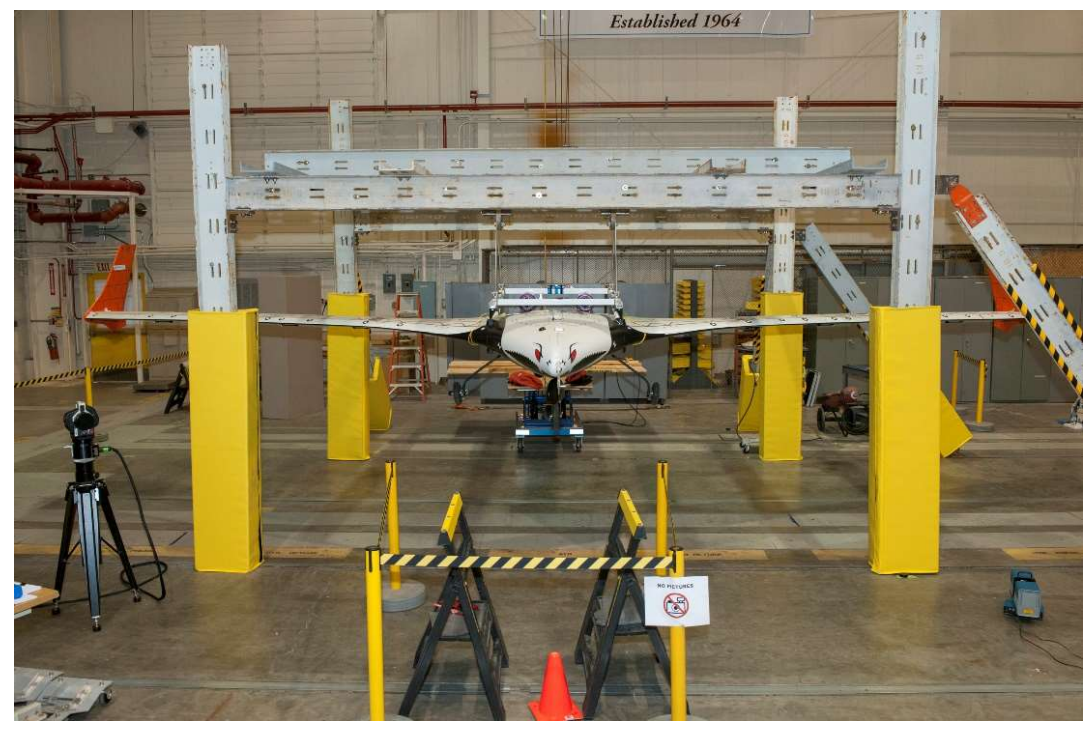

Fig. 22 The X-56A Multi-Utility Technology Testbed in moment of inertia testing configuration.

Four different instrumentation methods were used to capture the oscillations and time: the laser-tracker system; the inertial measurement unit (IMU); the onboard aircraft IMU; and a simple stopwatch. The laser-tracker system used was the API Laser Tracker3 System (Automated Precision, Inc., Rockville, Maryland, USA). Six laser reference points were placed on the ground around the test setup to establish a coordinate system and measure the dimensions of the test setup area. A laser reflective puck was installed on the forward center horizontal unistrut beam of the lifting frame to track and measure the period of the test article swings. A MicroStrain 3DM-GX4-45 IMU (LORD MicroStrain, Williston, Vermont, USA) was used for this test. The IMU and its battery were installed on top of the aft center horizontal unistrut beam of the lifting frame, and connected to a wireless adapter to stream the data wirelessly to a laptop for processing. The X-56A MUTT onboard IMU was only used to collect configuration data by way of the vehicle management computer. A stopwatch was used to time the number of cycles desired in order to calculate the period of the oscillations. 


\section{Test Narrative}

Before each test configuration, weight and CG were documented in the test checklist. At the beginning of the test, a laser track of the ground reference points was performed to establish the dimensions and coordinates of the test area. For all test runs in all test configurations, data were taken for 10 test runs of 25 swing cycles each. Data for reference heights and leveling information also were gathered. Lifting-hardware-only tests in the long and short pendulum configurations were completed first. The X-56A MUTT was manually guided from the back of the lifting frame and allowed to swing back and forth before being released to swing freely and allowing data to be gathered; this same method was applied to the test runs. For one test run, lateral motion was observed during the swings and the run had to be repeated several times to ensure that no lateral motion was coupling. Testing in the short and long pendulum conditions, respectively, also were performed.

\section{Results}

The IYY pitch inertia results between the short and long pendulum conditions for only the X-56A MUTT (after factoring out the lifting frame hardware) differed by approximately 2.5 percent. Differences were not large as mass updates were tracked and included prior to performing the IYY MOI test. Error was measured using the propagation of uncertainty method.[16] The combined XCG and pitch MOI uncertainty calculation was only performed for the short pendulum length and had a 6.8-percent uncertainty, which was acceptable for this test.

\section{Challenges}

The MOI test setup incorporated multiple improvements and lessons learned from previous MOI tests. The knifeedges and collars used were oversized for a vehicle the size of the X-56A MUTT; however, the knife-edges incorporated improvements such as curving out the V-channels to reduce friction. As well, hardware was already readily available for interfacing with the X-56 MUTT. Accurate calculation of the MOI requires meticulous measurement of periods and lengths. Measuring the period using four separate systems may seem redundant, but doing so provided an independent check on the period measurement and helped reduce uncertainty.

\section{Lessons Learned}

\section{A. Wing-only Strongback Ground Vibration Test:}

1) Install additional tri-axial accelerometers at the winglet for better resolution of mode shapes.

2) Power-on actuators to prevent drooping from excitations.

3) Ensure sufficient lighting for operation of the photogrammetry system.

4) In order to acquire useful data from the FOSS system, higher shaker-excitation levels were required. Review data and iterate on software settings in order to ensure acquisition of useful data.

\section{B. Full-Aircraft Ground Vibration Test:}

1) Additional scrutiny is required when using multiple bungees because of the increased risk of coupling between bungees or with the rigid-body modes of the flexible vehicle.

2) Eliminate all potential degrees of freedom (that is, the metal sling rotation around the bungee) that could interfere with the rigid-body structural modes.

3) Perform pre-test analysis with various boundary conditions to identify potential boundary-condition sensitivities for obtaining quality data.

4) When possible, instrument the soft-support system (bungees and hardware) to verify their independence from the structural modes and to assist with any required troubleshooting.

5) Ensure that the bungees are sufficiently flexible, and minimize interference in all degrees of freedom of interest.

\section{Aircraft Pitch Moment of Inertia Test:}

1) When using knife-edges, curved-out V-channels further reduce friction.

2) Use multiple sources for period measurement as a sanity check for accurate data.

\section{Future Work}

The X-56A MUTT was designed as a multi-utility technology testbed to accommodate different wing configurations using a common centerbody for high-risk flight-testing. In addition, the aircraft can be used to test a variety of sensors, control schemes, and control effectors for various configurations. The potential exists for future wings and vehicle configurations for the X-56A MUTT that will require ground structural testing to validate and 
updated a FEM. Boundary conditions are very important to successful GVTs. When dealing with flexible vehicles, the interaction of flexible mode shapes with the rigid-body dynamics must be considered. Future ground tests should incorporate lessons learned while leveraging previous experience to obtain quality GVT data.

\section{Conclusion}

This paper described the X-56 Multi-Utility Technology Testbed (MUTT) structural ground test setup and analysis efforts for the moment of inertia test and wing-only and full-vehicle ground vibration tests (GVTs). Model correlation steps and lessons learned were explained. There were challenges in the structural model correlation for the empty and full-fuel configuration for the symmetric wing first bending (SW1B) mode; the GVT did not capture this frequency shift. The leading hypothesis is that the lack of capture was due to a flaw in the pitch degrees of freedom (DOF) that allowed the vehicle to reorient on the bungee between fuel conditions; this reorientation likely affected the rigid-body pitch and plunge and SW1B frequencies. The pitch DOF affected the SW1B frequency as the vehicle reoriented with the center of gravity below the hanging point. Another hypothesis is that the SW1B mode is much more sensitive to uncertainty error from curve-fitting techniques because of its low frequency value. Moment of inertia testing to determine the pitch inertia was also performed. Experimental results were consistent with the expected pitch inertia that was analytically calculated.

\section{Acknowledgements}

The authors thank the National Aeronautics and Space Administration Armstrong Flight Research Center Flight Loads Laboratory staff for their assistance with the structural dynamics ground-test setups and execution. The authors also acknowledge the assistance of the X-56 project team during testing. The support of Claudia Herrera and Rachel Saltzman of the Dynamics group during ground testing is gratefully acknowledged. ATA Engineering personnel assisted with the aircraft ground vibration test execution and provided guidance during the bungee configuration changes.

\section{References}

[1] Beranek, J., Nicolai, L., Buonanno, M., Burnett, E., Atkinson, C., Holm-Hansen, B., et al., “Conceptual Design of a Multi-utility Aeroelastic Demonstrator," AIAA Paper 2010-9350, Sep. 2010.

doi: 10.2514/6.2010-9350.

[2] Ryan, J. J. Bosworth, J. T., Burken, J. J., and Suh, P. M. "Current and Future Research in Active Control of Lightweight, Flexible Structures Using the X-56 Aircraft” AIAA Paper 2014-0597, Jan. 2014.

doi: $10.2514 / 6.2014-0597$

[3] Chin, A. W., and Truong, S. S., "X-56A Buckeye Structural Dynamics Testing, Analysis, and Model Updating Report," draft NASA/RS Internal Report, Feb. 2019. Available from the authors of this paper.

[4] Ko, W. L., Richards, W. L., and Fleischer, V. T. "Applications of Ko Displacement Theory to the Deformed Shape Predictions of the Doubly-Tapered Ikhana Wing," NASA/TP-2009-214652, Oct. 2009.

[5] Bakalyar, J., and Jutte, C., "Validation Tests of Fiber Optic Strain-Based Operational Shape and Load Measurements," AIAA Paper 2012-1904, Apr. 2012.

doi: 10.2514/6.2019-1904

[6] Chan, H. M., "Fiber Optic Sensing System (FOSS) at NASA Armstrong Flight Research Center (AFRC): Summary and Recent Deployments," Sep. 2018, URL: https://ntrs.nasa.gov/archive/nasa/casi.ntrs.nasa.gov/20180007391.pdf [retrieved 21 Nov. 2019]

[7] Pena, F., Martins, B. L., and Richards, W. L., “Active In-flight Load Redistribution Utilizing Fiber-Optic Shape Sensing and Multiple Control Surfaces,” NASA/TM-2018-219741, Feb. 2018.

[8] Military Standard, "Test Requirements for Launch, Upper-stage, and Space Vehicles," MIL-STD-1540C, Section 6.2.10, Sep. 1994.

[9] NASA Technical Standard, "Load Analysis of Spacecraft and Payloads," NASA-STD-5002, Section 4.2.6.d, Jun. 1996.

[10] Green, M. W., "Measurement of the Moments of Inertia of Full Scale Airplanes," NACA Technical Note No. 265, Sep. 1927.

[11] Miller, M. P., "An Accurate Method of Measuring the Moments of Inertia of Airplanes," NACA Technical Note No. 351, Oct. 1930.

[12] Miller, M. P., and Soule H. A., "Moments of Inertia of Several Airplanes," NACA Technical Note No. 375, May 1931. 
[13] Soule, H. A., and Miller, M. P., "The Experimental Determination of the Moments of Inertia of Airplanes," NACA Report No. 467, Jan. 1934.

[14] Turner, H. L., "Measurement of the Moments of Inertia of an Airplane by a Simplified Method," NACA Technical Note 2201, Oct. 1950.

[15] Gracey W., "The Additional Mass-Effect of Plates as Determined by Experiments," NACA Report No. 707, 1941.

[16] Kirchner, J., "Data Analysis Toolkit \#5: Uncertainty Analysis and Error Propagation," Berkeley Seismology Laboratory, University of California,

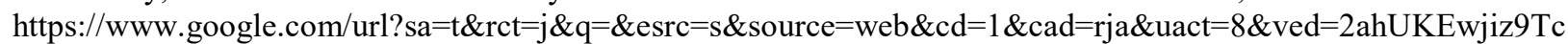
pIjmAhXqpVkKHTrdAAUQFjAAegQIARAC\&url=http\%3A\%2F\%2Fseismo.berkeley.edu\%2F kirchner\%2Feps 120\%2FToolkits\%2FToolkit_05.pdf\&usg=AOvVaw2vA_wcwmDfoELyi0myjwav [retrieved 2 Dec 2019]. 